IZA DP No. 9491

New Evidence on Linear Regression and Treatment Effect Heterogeneity

Tymon Stoczyński

November 2015 


\title{
New Evidence on Linear Regression and Treatment Effect Heterogeneity
}

\author{
Tymon Słoczyński \\ Warsaw School of Economics \\ and IZA
}

\section{Discussion Paper No. 9491 \\ November 2015}

\author{
IZA \\ P.O. Box 7240 \\ 53072 Bonn \\ Germany \\ Phone: +49-228-3894-0 \\ Fax: +49-228-3894-180 \\ E-mail: iza@iza.org
}

\begin{abstract}
Any opinions expressed here are those of the author(s) and not those of IZA. Research published in this series may include views on policy, but the institute itself takes no institutional policy positions. The IZA research network is committed to the IZA Guiding Principles of Research Integrity.

The Institute for the Study of Labor (IZA) in Bonn is a local and virtual international research center and a place of communication between science, politics and business. IZA is an independent nonprofit organization supported by Deutsche Post Foundation. The center is associated with the University of Bonn and offers a stimulating research environment through its international network, workshops and conferences, data service, project support, research visits and doctoral program. IZA engages in (i) original and internationally competitive research in all fields of labor economics, (ii) development of policy concepts, and (iii) dissemination of research results and concepts to the interested public.
\end{abstract}

IZA Discussion Papers often represent preliminary work and are circulated to encourage discussion. Citation of such a paper should account for its provisional character. A revised version may be available directly from the author. 


\section{ABSTRACT}

\section{New Evidence on Linear Regression and Treatment Effect Heterogeneity ${ }^{\star}$}

It is standard practice in applied work to rely on linear least squares regression to estimate the effect of a binary variable ("treatment") on some outcome of interest. In this paper I study the interpretation of the regression estimand when treatment effects are in fact heterogeneous. I show that the coefficient on treatment is identical to the outcome of the following three-step procedure: first, calculate the linear projection of treatment on the vector of other covariates ("propensity score"); second, calculate average partial effects for both groups of interest ("treated" and "controls") from a regression of outcome on treatment, the propensity score, and their interaction; third, calculate a weighted average of these two effects, with weights being inversely related to the unconditional probability that a unit belongs to a given group. Each of these steps is potentially problematic, but this last property - the reliance on implicit weights which are inversely related to the proportion of each group can have particularly severe consequences for applied work. To illustrate the importance of this result, I perform Monte Carlo simulations as well as replicate two applied papers: Berger, Easterly, Nunn and Satyanath (2013) on the effects of successful CIA interventions during the Cold War on imports from the US; and Martinez-Bravo (2014) on the effects of appointed officials on village-level electoral results in Indonesia. In both cases some of the conclusions change dramatically after allowing for heterogeneity in effects.

JEL Classification: C21, C52, D72, F14, 017

Keywords: heterogeneity, linear regression, ordinary least squares, propensity score, treatment effects

Corresponding author:

Tymon Słoczyński

Department of Economics I

Warsaw School of Economics

ul. Madalinskiego 6/8 p. 228

02-513 Warszawa

Poland

E-mail: tymon.sloczynski@gmail.com

\footnotetext{
* This paper has benefited from many comments and discussions with Jeffrey Wooldridge, for which I am deeply grateful. I also thank Alberto Abadie, Joshua Angrist, Marco Caliendo, Todd Elder, Alfonso Flores-Lagunes, Keisuke Hirano, Macartan Humphreys, Guido Imbens, Krzysztof Karbownik, Patrick Kline, Paweł Królikowski, Nicholas Longford, Łukasz Marć, Michał Myck, Gary Solon, Michela Tincani, Joanna Tyrowicz, Rudolf Winter-Ebmer, and seminar and conference participants at many institutions for useful comments and discussions. I acknowledge financial support from the National Science Centre (grant DEC-2012/05/N/HS4/00395), the Foundation for Polish Science (a START scholarship), and the "Weź stypendium-dla rozwoju" scholarship program.
} 


\section{Introduction}

Many applied researchers study the effect of a binary variable ("treatment") on the expected value of some outcome of interest, holding fixed a vector of other covariates. As noted by Imbens (2015), despite the availability of a large number of semi- and nonparametric estimators for average treatment effects, applied researchers typically continue to use conventional regression methods. In particular, it is standard practice in applied work to use ordinary least squares (OLS) to estimate

$$
y_{i}=\alpha+\tau d_{i}+X_{i} \beta+\varepsilon_{i}
$$

where $y$ denotes the outcome, $d$ denotes the binary variable of interest, and $X$ denotes the row vector of other covariates (control variables); $\hat{\tau}$ is then usually interpreted as the average treatment effect (ATE). This simple estimation strategy is used in a large number of applied papers in leading economics journals, as well as in other disciplines. ${ }^{1}$

The great appeal of linear least squares regression comes from its simplicity. At the same time, however, a large body of evidence demonstrates the empirical importance of heterogeneity in effects (see, e.g., Heckman, 2001; Bitler, Gelbach and Hoynes, 2006, 2008) which is explicitly ruled out by the model in (1). In this paper, therefore, I study the interpretation of the least squares estimand in the homogeneous linear model when treatment effects are in fact heterogeneous. I derive a new theoretical result which demonstrates that $\hat{\tau}$ is identical to the outcome of the following three-step procedure: in the first step, calculate the linear projection of $d$ on $X$, i.e. the "propensity score" from the linear probability model; in the second step, regress $y$ on $d$, the propensity score, and their interaction-and calculate average partial effects from this model for both groups of interest ("treated" and "controls"); in the third step, calculate a weighted average of these two effects-with weights being inversely related to the unconditional probability that a unit belongs to a given group. In consequence, when the proportion of one group increases, the weight on the effect on this group decreases. The limit of the regression estimand, as the proportion of treated units approaches unity, is the average treatment effect on the controls. I also establish conditions under which linear regression recovers

$$
\tau=\mathrm{P}(d=1) \cdot \tau_{A T C}+\mathrm{P}(d=0) \cdot \tau_{A T T}
$$

\footnotetext{
${ }^{1}$ See, e.g., Black, Smith, Berger and Noel (2003), Fryer and Levitt (2004), Gittleman and Wolff (2004), Almond, Chay and Lee (2005), Elder, Goddeeris and Haider (2010), Fryer and Greenstone (2010), Fryer and Levitt (2010), Lang and Manove (2011), Alesina, Giuliano and Nunn (2013), Berger, Easterly, Nunn and Satyanath (2013), Bond and Lang (2013), Rothstein and Wozny (2013), and Martinez-Bravo (2014).
} 
instead of

$$
\tau_{A T E}=\mathrm{P}(d=1) \cdot \tau_{A T T}+\mathrm{P}(d=0) \cdot \tau_{A T C},
$$

where $\tau_{A T E}$ denotes the average treatment effect, $\tau_{A T T}$ denotes the average treatment effect on the treated, and $\tau_{A T C}$ denotes the average treatment effect on the controls; also, $\mathrm{P}(d=1)$ and $\mathrm{P}(d=0)$ denote population proportions of treated and control units, respectively. As a consequence of the disparity between (2) and (3), in many empirical applications the linear regression estimates might not be close to any of the average treatment effects of interest.

This paper therefore contributes to a growing field of research in econometrics which studies the interpretation of various estimation methods when their underlying assumption of homogeneity in effects is violated. See, e.g., Wooldridge (2005), Løken, Mogstad and Wiswall (2012), Chernozhukov, Fernández-Val, Hahn and Newey (2013), Imai and Kim (2013), and Gibbons, Suárez Serrato and Urbancic (2014) for studies of fixed effects (FE) methods as well as Imbens and Angrist (1994), Angrist, Graddy and Imbens (2000), Løken et al. (2012), Kolesár (2013), and Dieterle and Snell (2014) for studies of instrumental variables (IV) estimators. ${ }^{2}$ Also, the interpretation of the coefficient on a binary variable in linear least squares regression is studied by Angrist (1998) and Humphreys (2009), and both of these papers consider a saturated model for covariates, i.e. the estimating equation includes a binary variable for each combination of covariate values ("stratum"). ${ }^{3}$ In this restricted setting, Angrist (1998) demonstrates that the weights underlying linear regression are proportional to the variance of treatment in each stratum. ${ }^{4}$ Humphreys (2009) extends this result and shows that the linear regression estimand is bounded by both group-specific average treatment effects whenever treatment assignment probabilities are monotonic in stratum-specific effects. In this paper I complement these previous results by relaxing the saturated model restriction and still deriving a closed-form expression for the regression estimand-in terms of group-specific average treatment effects ( $\tau_{\text {ATT }}$ and $\left.\tau_{A T C}\right)$. This formulation is very attractive because each regression estimate can now be expressed as a weighted average of two estimates of $\tau_{A T T}$ and $\tau_{A T C}$. Moreover, the weights

\footnotetext{
${ }^{2}$ This literature is also related to Heckman and Vytlacil (2005), Heckman, Urzua and Vytlacil (2006), and Heckman and Vytlacil (2007) who provide an interpretation of various estimators, conditional on $X$, as weighted averages of marginal treatment effects.

${ }^{3}$ Also, the interpretation of the coefficient on a continuous variable in linear regression is studied by Yitzhaki (1996), Deaton (1997), Angrist and Krueger (1999), Løken et al. (2012), and Solon, Haider and Wooldridge (2015).

${ }^{4}$ A similar result for nonsaturated models is derived by Rhodes (2010) and Aronow and Samii (2015). In both of these papers the regression estimand is interpreted as a weighted average of individual-level treatment effects. In this paper I provide an alternative formulation, in which this estimand is interpreted as a weighted average of group-specific average treatment effects $\left(\tau_{A T T}\right.$ and $\left.\tau_{A T C}\right)$.
} 
are also easily computed - and they are always nonnegative and sum to one.

To illustrate the importance of this result, I perform Monte Carlo simulations and replicate two influential applied papers: Berger et al. (2013) and Martinez-Bravo (2014). Both of these papers study the effect of a binary variable (US interventions in foreign countries and whether the local officials are appointed or elected, respectively) on the expected value of some outcome of interest, and both rely on a model with homogeneous effects which is estimated using OLS. Berger et al. (2013) conclude that CIA interventions during the Cold War led to a dramatic increase in imports from the US, without affecting exports to the US, aggregate imports, and aggregate exports. However, when I present the implied estimates of the average effect of CIA interventions on intervened countries and nonintervened countries, it becomes clear that this conclusion is driven by the large discrepancy in the effect on nonintervened countries across specifications-while this parameter is arguably of little interest in this application. ${ }^{5}$ The implied estimates of the average effect on intervened countries are all significantly positive and remarkably stable across specifications-and suggest that CIA interventions led to an (unbelievably large) increase in all measures of international trade in intervened countries. Surprisingly, when I relax the linear relationship between potential outcomes and the propensity score, and use a matching estimator, these effects often become significantly negative.

My second empirical application concentrates on the effects of appointed village heads on electoral results. In a recent paper, Martinez-Bravo (2014) studies the outcome of the first democratic election in Indonesia after the fall of the Soeharto regime. She concludes that Golkar, i.e. Soeharto's party, was more likely to win in kelurahan villages which had appointed village heads, compared with desa villages which had elected village heads. In this paper, however, I document that linear regression provides a very poor approximation to the average effect of appointed officials. Note that kelurahan villages constitute a small fraction of this data set, while my theoretical result suggests that linear regression will therefore attach nearly all of the weight to the average effect of appointed officials in these villages, and not in desa. This is confirmed in my analysis, and I conclude that the average treatment effect, i.e. the average difference in electoral results between similar kelurahan and desa villages, is not significantly different from zero.

\footnotetext{
${ }^{5}$ Imagine, for example, estimating the effect of CIA interventions in Australia, Canada, and the UK on their imports from the US. Note that the measure of CIA interventions equals one "if the CIA either installed a foreign leader or provided covert support for the regime once in power" (Berger et al., 2013).
} 


\section{Theoretical Results}

As before, let $y$ denote the outcome, let $d$ denote the binary variable of interest ("treatment"), and let $X$ denote the row vector of other covariates. If $\mathrm{L}(\cdot \mid \cdot)$ denotes the linear projection, this paper is concerned with the interpretation of $\tau$ in

$$
\mathrm{L}(y \mid 1, d, X)=\alpha+\tau d+X \beta
$$

when the population linear model is possibly incorrect. Before giving my main theoretical results, however, I introduce further definitions. In particular, let

$$
\rho=\mathrm{P}(d=1)
$$

denote the unconditional probability of "treatment" and let

$$
p(X)=\mathrm{L}(d \mid 1, X)=\alpha_{s}+X \beta_{s}
$$

denote the "propensity score" from the linear probability model. ${ }^{6}$ Note that $p(X)$ is the best linear approximation to the true propensity score. It is also helpful to introduce two linear projections of $y$ on $p(X)$, separately for $d=1$ and $d=0$, namely

$$
\mathrm{L}[y \mid 1, p(X)]=\alpha_{1}+\gamma_{1} \cdot p(X) \quad \text { if } \quad d=1
$$

and also

$$
\mathrm{L}[y \mid 1, p(X)]=\alpha_{0}+\gamma_{0} \cdot p(X) \quad \text { if } \quad d=0 .
$$

Note that equations (6) to (8) are definitional. I do not assume that these linear projections correspond to well-specified population models and I do not put any restrictions on the underlying data-generating process. Similarly, I define the average partial effect of $d$ as

$$
\tau_{A P E}=\left(\alpha_{1}-\alpha_{0}\right)+\left(\gamma_{1}-\gamma_{0}\right) \cdot \mathrm{E}[p(X)]
$$

as well as the average partial effect of $d$ on group $j(j=0,1)$ as

$$
\tau_{A P E \mid d=j}=\left(\alpha_{1}-\alpha_{0}\right)+\left(\gamma_{1}-\gamma_{0}\right) \cdot \mathrm{E}[p(X) \mid d=j]
$$

\footnotetext{
${ }^{6}$ Note that this "propensity score" does not need to have any behavioral interpretation. For example, $d$ can be an attribute, in the sense of Holland (1986), and therefore does not need to constitute a feasible "treatment" in any "ideal experiment" (Angrist and Pischke, 2009). Although it might be difficult, for example, to conceptualize the "propensity score" for gender or race, it does not matter for this definition.
} 
If $d$ is unconfounded conditional on $X$ and there is complete overlap in the conditional distributions of $X$ given $d=1$ and $d=0$, then the propensity score theorem of Rosenbaum and Rubin (1983) implies that $\tau_{A P E}, \tau_{A P E \mid d=1}$, and $\tau_{A P E \mid d=0}$ have a useful interpretation as the average treatment effect, the average treatment effect on the treated, and the average treatment effect on the controls, respectively. It should be stressed, however, that the main result of this paper (Theorem 1) is more general and does not require unconfoundedness or overlap.

Theorem 1 (Decomposition of the Linear Regression Estimand) Define $\tau$ as in (4) and define $\tau_{A P E \mid d=1}$ and $\tau_{A P E \mid d=0}$ as in $(10)$. Let $\mathrm{V}(\cdot \mid \cdot)$ denote the conditional variance. Then,

$$
\begin{aligned}
\tau & =\frac{\rho \cdot \mathrm{V}[p(X) \mid d=1]}{\rho \cdot \mathrm{V}[p(X) \mid d=1]+(1-\rho) \cdot \mathrm{V}[p(X) \mid d=0]} \cdot \tau_{A P E \mid d=0} \\
& +\frac{(1-\rho) \cdot \mathrm{V}[p(X) \mid d=0]}{\rho \cdot \mathrm{V}[p(X) \mid d=1]+(1-\rho) \cdot \mathrm{V}[p(X) \mid d=0]} \cdot \tau_{A P E \mid d=1}
\end{aligned}
$$

Theorem 1 shows that $\tau$, the linear regression estimand, can be expressed as a weighted average of $\tau_{A P E \mid d=1}$ and $\tau_{A P E \mid d=0}$, with nonnegative weights which always sum to one. ${ }^{7}$ The definition of $\tau_{A P E \mid d=j}$ makes it clear that the regression estimand is always identical to the outcome of a particular three-step procedure. In the first step, we obtain $p(X)$, i.e. the "propensity score". In applied work, however, it is quite rare to estimate propensity scores using the linear probability model, probably because the estimated probabilities are not ensured to be strictly between zero and one-and therefore it is important to note that linear regression is implicitly based on this procedure. Next, in the second step, we obtain $\tau_{A P E \mid d=1}$ and $\tau_{A P E \mid d=0}$ from a regression of $y$ on $d, p(X)$, and their interaction. Again, similar procedures are rarely used in practice and are generally not recommended, because it is difficult to motivate a linear relationship between potential outcomes and the propensity score (see, e.g., Imbens and Wooldridge, 2009). According to Theorem 1 , however, linear regression is implicitly based on this restrictive model. Finally, in the third step, we calculate a weighted average of $\tau_{A P E \mid d=1}$ and $\tau_{A P E \mid d=0}$. The weight which is placed by linear regression on $\tau_{A P E \mid d=1}$ is increasing in $\mathrm{V}[p(X) \mid d=0]$ and $1-\rho$ and the weight which is placed on $\tau_{A P E \mid d=0}$ is increasing in $\mathrm{V}[p(X) \mid d=1]$ and $\rho$.

At first, this weighting scheme might be seen as surprising: the more units belong to group $j(d=j, j=0,1)$, the less weight is placed on $\tau_{A P E \mid d=j}$, i.e. the effect on this group. To aid intuition, recall that the linear regression model is based on the assumption

\footnotetext{
${ }^{7}$ See Appendix A for the proof of Theorem 1.
} 
of homogeneity in effects; in particular, $\tau_{A P E}=\tau_{A P E \mid d=1}=\tau_{A P E \mid d=0}$. Notice also that $\tau_{A P E \mid d=1}\left(\tau_{A P E \mid d=0}\right)$ is estimated, in general, using the data from units with $d=0(d=1)$. This can be more easily seen from a particular reformulation of equation (10). Because the regression line passes through the point of means of the data, the average partial effects of $d$ on both groups of interest can also be expressed as

$$
\tau_{A P E \mid d=1}=\mathrm{E}(y \mid d=1)-\left\{\alpha_{0}+\gamma_{0} \cdot \mathrm{E}[p(X) \mid d=1]\right\}
$$

and also

$$
\tau_{A P E \mid d=0}=\left\{\alpha_{1}+\gamma_{1} \cdot \mathrm{E}[p(X) \mid d=0]\right\}-\mathrm{E}(y \mid d=0) .
$$

What follows, we need to estimate $\alpha_{0}$ and $\gamma_{0}$ (but not $\alpha_{1}$ or $\gamma_{1}$ ) in order to obtain an estimate of $\tau_{A P E \mid d=1}$. Also, we have to estimate $\alpha_{1}$ and $\gamma_{1}$ (but not $\alpha_{0}$ or $\gamma_{0}$ ) in order to estimate $\tau_{A P E \mid d=0}$. Therefore, if effects are assumed to be homogeneous, we want to place more (less) weight on $\hat{\tau}_{A P E \mid d=1}$ when the proportion of units with $d=1$ decreases (increases), as this will improve efficiency in estimating $\tau_{A P E}$. However, the opposite holds true if effects are allowed to be heterogeneous, and then using linear least squares regression is likely to introduce bias.

There are several interesting corollaries of Theorem 1. Similar to the discussion above, Corollary 1 clarifies the causal interpretability of the linear regression estimand.

Corollary 1 (Causal Interpretation of the Linear Regression Estimand) Suppose that $d$ is unconfounded conditional on $X$ and that the population models for $d$ and $y$ are linear in $X$ and $p(X)$, respectively. Let $\mathrm{D}(\cdot \mid \cdot)$ denote the conditional distribution and suppose that the support of $\mathrm{D}(X \mid d=1)$ overlaps completely with that of $\mathrm{D}(X \mid d=0)$. Then, Theorem 1 implies that

$$
\begin{aligned}
\tau & =\frac{\rho \cdot \mathrm{V}[p(X) \mid d=1]}{\rho \cdot \mathrm{V}[p(X) \mid d=1]+(1-\rho) \cdot \mathrm{V}[p(X) \mid d=0]} \cdot \tau_{A T C} \\
& +\frac{(1-\rho) \cdot \mathrm{V}[p(X) \mid d=0]}{\rho \cdot \mathrm{V}[p(X) \mid d=1]+(1-\rho) \cdot \mathrm{V}[p(X) \mid d=0]} \cdot \tau_{A T T} .
\end{aligned}
$$

In other words, if strong ignorability (unconfoundedness and overlap) holds and the population models for $d$ and $y$ are correctly specified as linear in $X$ and $p(X)$, respectively, the weighting scheme from Theorem 1 will apply to $\tau_{A T T}$ and $\tau_{A T C}$. In particular, the weight which is placed on $\tau_{A T T}$ is increasing in $1-\rho$ and the weight which is placed on $\tau_{A T C}$ is increasing in $\rho$. Corollary 2 shows that the relationship between $\tau$ and $\rho$ is in fact monotonic. The only case where $\tau$ is unrelated to $\rho$ occurs when both group-specific average partial effects are equal. 
Corollary 2 Theorem 1 implies that

$$
\frac{\mathrm{d} \tau}{\mathrm{d} \rho}=\frac{\mathrm{V}[p(X) \mid d=1] \cdot \mathrm{V}[p(X) \mid d=0] \cdot\left(\tau_{A P E \mid d=0}-\tau_{A P E \mid d=1}\right)}{\{\rho \cdot \mathrm{V}[p(X) \mid d=1]+(1-\rho) \cdot \mathrm{V}[p(X) \mid d=0]\}^{2}} .
$$

Therefore, if $\tau_{A P E \mid d=1}>\tau_{A P E \mid d=0}$, then $\frac{\mathrm{d} \tau}{\mathrm{d} \rho}<0$. With an increase in $\rho, \tau$ deviates from $\tau_{A P E \mid d=1}$ towards $\tau_{A P E \mid d=0}$. Similarly, if $\tau_{A P E \mid d=1}<\tau_{A P E \mid d=0}$, then $\frac{\mathrm{d} \tau}{\mathrm{d} \rho}>0$. Again, with an increase in $\rho, \tau$ deviates from $\tau_{A P E \mid d=1}$ towards $\tau_{A P E \mid d=0}$. In other words, when $\tau_{A P E \mid d=1} \neq$ $\tau_{A P E \mid d=0}$ and the proportion of one group changes, the weight on the effect on this group always changes in the opposite direction.

Corollary 3 Theorem 1 implies that

$$
\lim _{\rho \rightarrow 1} \tau=\tau_{A P E \mid d=0} \quad \text { and } \quad \lim _{\rho \rightarrow 0} \tau=\tau_{A P E \mid d=1} .
$$

According to Corollary 3, another consequence of Theorem 1 is that the linear regression estimand approaches the average partial effect on group $j$ whenever-in the limit-the proportion of units with $d=j$ goes to zero. Under a causal interpretation, when nearly everyone is treated, we get very close to the average treatment effect on the controls; conversely, when nearly nobody gets treated, we approach the average treatment effect on this (nearly nonexistent) group. Therefore, Corollary 3 provides the foundation for a simple rule of thumb: if nearly everyone belongs to group $j$, linear least squares regression will approximately provide an estimate of the effect on the other group. As noted previously, this is a reasonable property under the assumption of homogeneity in effects: if nearly everyone belongs to group $j$, then we can estimate the effect on the other group, and not on group $j$, with relative precision. This argument arises from the fact that we use the data from units with $d=0(d=1)$ to estimate the counterfactual for units with $d=1$ $(d=0)$; therefore, the precision of the estimates for group $j$ is increasing in the amount of data from the other group. If we maintain the assumption of homogeneity in effects, then we should indeed place little weight on the effect for the large group. This logic, however, is no longer applicable when effects are allowed to be heterogeneous.

Another consequence of Theorem 1 is described by Corollary 4 . We can start with noting that the average partial effect of $d$ can be written as

$$
\tau_{A P E}=\rho \cdot \tau_{A P E \mid d=1}+(1-\rho) \cdot \tau_{A P E \mid d=0} .
$$


Then, Corollary 4 provides a condition under which linear regression reverses these "natural" weights on $\tau_{A P E \mid d=1}$ and $\tau_{A P E \mid d=0}$.

Corollary 4 Suppose that $\mathrm{V}[p(X) \mid d=1]=\mathrm{V}[p(X) \mid d=0]$. Then, Theorem 1 implies that

$$
\tau=\rho \cdot \tau_{A P E \mid d=0}+(1-\rho) \cdot \tau_{A P E \mid d=1} .
$$

Precisely, if the variance of the "propensity score" is equal in both groups of interest, then the linear regression estimand is equal to a weighted average of both group-specific average partial effects, with reversed weights attached to these effects. Namely, the proportion of units with $d=1$ is used to weight the average partial effect of $d$ on group zero and the proportion of units with $d=0$ is used to weight the average partial effect of $d$ on group one. Therefore, there is only one situation in which Corollary 4 allows the linear regression estimand to be equal to the average partial effect of $d$, and this occurs whenever not only $\mathrm{V}[p(X) \mid d=1]=\mathrm{V}[p(X) \mid d=0]$ but also $\rho=1-\rho=\frac{1}{2}$. Moreover, Corollary 5 provides a more general condition under which we can recover the average partial effect of $d$ using linear regression.

Corollary 5 Suppose that $\tau_{A P E \mid d=1} \neq \tau_{A P E \mid d=0}$. Then, Theorem 1 implies that

$$
\tau=\tau_{A P E} \quad \text { if and only if } \quad \frac{\mathrm{V}[p(X) \mid d=1]}{\mathrm{V}[p(X) \mid d=0]}=\left(\frac{1-\rho}{\rho}\right)^{2} .
$$

According to Corollary 5, the linear regression estimand is equal to the average partial effect of $d$ only in a special case, where the ratio of the conditional variances of the "propensity score" is equal to the square of the reversed ratio of population proportions of treated and control units. Corollary 5 can therefore be seen as an example of the "knife-edge special case" of consistency of OLS, similar to Solon et al. (2015).

It is also useful to discuss the relationship between this paper and the previous results in Angrist (1998) and Humphreys (2009). On the one hand, there is limited overlap between Theorem 1 and these previous contributions, because they both restrict their attention to saturated models, in which the estimating equation includes a binary variable for each combination of covariate values ("stratum"). In this paper I provide a more general result which is not restricted to saturated models. On the other hand, some connections between these contributions can nevertheless be made. First, note that the baseline result in Angrist (1998) is derived for a model with only two strata. Appendix B demonstrates 
that this result follows from a special case of Theorem 1, in which $X$ is a single binary variable. Second, note that the main result in Humphreys (2009) means that the linear regression estimand is bounded by $\tau_{A T T}$ and $\tau_{A T C}$ if treatment assignment probabilities are monotonic in stratum-specific effects. According to Corollary 1 , the linear regression estimand lies within these bounds if, among other things, the population model for $y$ is linear in $p(X)$. In this case, however, treatment assignment probabilities are indeed monotonic in the effects of treatment. Therefore, the main condition from Humphreys (2009) is satisfied, and this demonstrates the relationship between his result and Corollary 1.

Also, there are several constructive solutions to the problem described in this section. First, it is sufficient to interact the variable of interest with other covariates, and then calculate its average partial effect on a given group (similar to equations (9) and (10)). This leads to an estimator which is sometimes referred to as "Oaxaca-Blinder" (Kline, 2011, 2014), "regression adjustment" (Wooldridge, 2010), "flexible OLS" (Khwaja, Picone, Salm and Trogdon, 2011), or even simply "regression" (Imbens and Wooldridge, 2009). Second, one can use any of the standard semi- and nonparametric estimators for average treatment effects, such as inverse probability weighting, matching, and other methods based on the propensity score (for a review, see Imbens and Wooldridge, 2009). Third, it might also help to estimate a model with homogeneous effects using weighted least squares (WLS). In particular, we might use the method of Lin (2013), in which equation (1) is estimated using WLS, with weights of $\frac{1-\rho}{\rho}$ for units with $d=1$ and weights of $\frac{\rho}{1-\rho}$ for units with $d=0$. However, note that-unlike in Lin (2013) who studies regression adjustments to experimental data-this estimator is consistent for the average partial effect of $d$ only in a special case, namely under the restrictive condition in Corollary 4, $\mathrm{V}[p(X) \mid d=1]=\mathrm{V}[p(X) \mid d=0]$, which is trivially true in an experimental setting, but not in a nonexperimental study. ${ }^{8}$

\section{Monte Carlo}

This section illustrates some of the key ideas of this paper using two Monte Carlo studies. The first study is similar to that in a recent paper by Busso, DiNardo and McCrary (2014), and it also attempts to mimic some features of the National Supported Work (NSW) data from LaLonde (1986). As in Busso et al. (2014), I focus on the subsample of African Amer-

\footnotetext{
${ }^{8}$ The crucial difference between regression adjustment in settings with experimental and with nonexperimental data comes from the fact that-under a causal interpretation-the average treatment effects on the treated and on the controls are necessarily equal-in expectation-in a randomized experiment, but not in a nonexperimental study. See Freedman (2008a,b), Deaton (2010), Schochet (2010), and Lin (2013) for recent discussions of regression adjustments to experimental data.
} 
icans as well as the comparison sample from the Panel Study of Income Dynamics (PSID), also restricted to African Americans. The outcome of interest is earnings in 1978, and the vector of covariates includes age, years of education, an indicator for being a high school dropout, marital status, earnings in 1974, earnings in 1975, employment status in 1974, and employment status in 1975. There are 156 treated and 624 control units in the final data set. In the first step, I estimate a probit model for treatment, and calculate a linear prediction from this model ("propensity score"). For each treatment status, I also estimate a regression model for outcome, and again calculate predicted values. In the second step, I draw with replacement 780 vectors which consist of: a vector of covariates, predicted values of both potential outcomes, and the estimated propensity score. In the third step, I draw iid normal errors, and use them - together with the estimated propensity score- to construct a treatment status for each unit. In the fourth step, separately for each treatment status, I draw iid normal errors, and use them-together with predicted values from both regression models-to construct potential outcomes for each unit. Finally, for each unit, the treatment status is used to determine which potential outcome is observed.

This procedure is used to draw 10,000 samples. For each sample, I estimate the effect of treatment using linear least squares regression-and then calculate the estimates of the average treatment effects on the treated and on the controls which are implied by Theorem 1. I also calculate the implicit weights on these estimates. Moreover, I estimate the average treatment effect, the average treatment effect on the treated, and the average treatment effect on the controls using the "flexible OLS" estimator-which amounts to regressing earnings in 1978 on the treatment status, all the covariates, and the full set of interactions between these covariates and the treatment status, and then calculating appropriate average partial effects. This estimator is equivalent to "regression adjustment" (Wooldridge, 2010) and "Oaxaca-Blinder" (Kline, 2011, 2014), as mentioned in Section 2; it is also expected to be unbiased, given the data-generating process described above. The true values of $\tau_{A T E}, \tau_{A T T}$, and $\tau_{A T C}$ are equal to $-\$ 5,022, \$ 2,229$, and $-\$ 6,835$, respectively.

The main results of this Monte Carlo study are summarized in Figure 1. Each of the "flexible OLS" estimators is unbiased for its respective parameter. At the same time, however, linear regression is very biased for each of $\tau_{A T E}, \tau_{A T T}$, and $\tau_{A T C}$, with the smallest bias in estimating $\tau_{A T T}$ (for more details, see Table C7 in Appendix C). Note that, on average, only $20 \%$ of the units are treated. Consequently, linear regression is usually closest to the true effect on the treated, the smaller group, although it is still biased for this parameter. Given Theorem 1, this result should not seem surprising.

Additional results are presented in Appendix C. In particular, Figure C3 and Table C7 provide evidence of poor finite-sample performance of both components of linear regres- 
Figure 1: Linear Regression and "Flexible OLS" Estimates of Average Treatment Effects

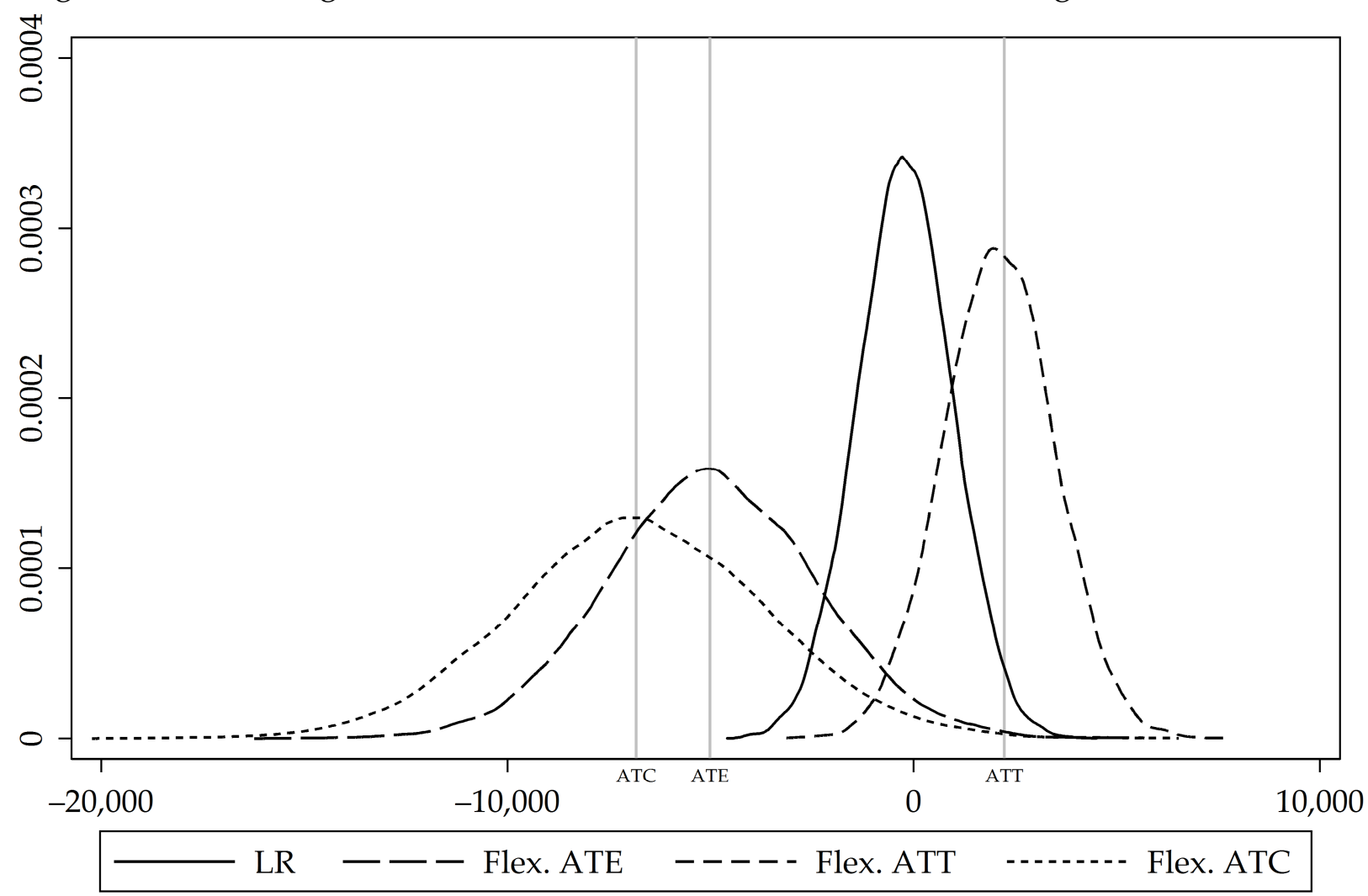

sion, i.e. the LPM-based estimators of the average treatment effect on the treated and the average treatment effect on the controls, which are implied by Theorem 1 . It is clear that both of these estimators - unlike the "flexible OLS" estimators in Figure 1-are biased for their respective parameters, given the data-generating process in this Monte Carlo study. This is most easily visible in Figure C3. Moreover, Table C8 summarizes the empirical distribution of the implicit weights which are used by linear regression to reweight both of these estimates. Even though, on average, $20 \%$ of the units are treated, the average weight on $\hat{\tau}_{A T T}$ is 0.640 , with the standard deviation of 0.038 (across 10,000 replications). In other words, under partial effect heterogeneity linear least squares regression is equivalent to a weighted average of two estimators, both of which are likely to perform poorly in finite samples, with weights which are also poorly chosen. It would be difficult to motivate the use of linear least squares regression under similar circumstances.

The second simulation study is based on the same sample of African Americans, and it uses a variant of the nonparametric bootstrap. In each replication, I retain the original sample of 156 treated units. I also draw a subsample of size $N_{0}$, with replacement, from the original sample of 624 control units-and append it to the sample of treated units. 
Figure 2: Linear Regression Estimates for Different Values of $N_{0}$

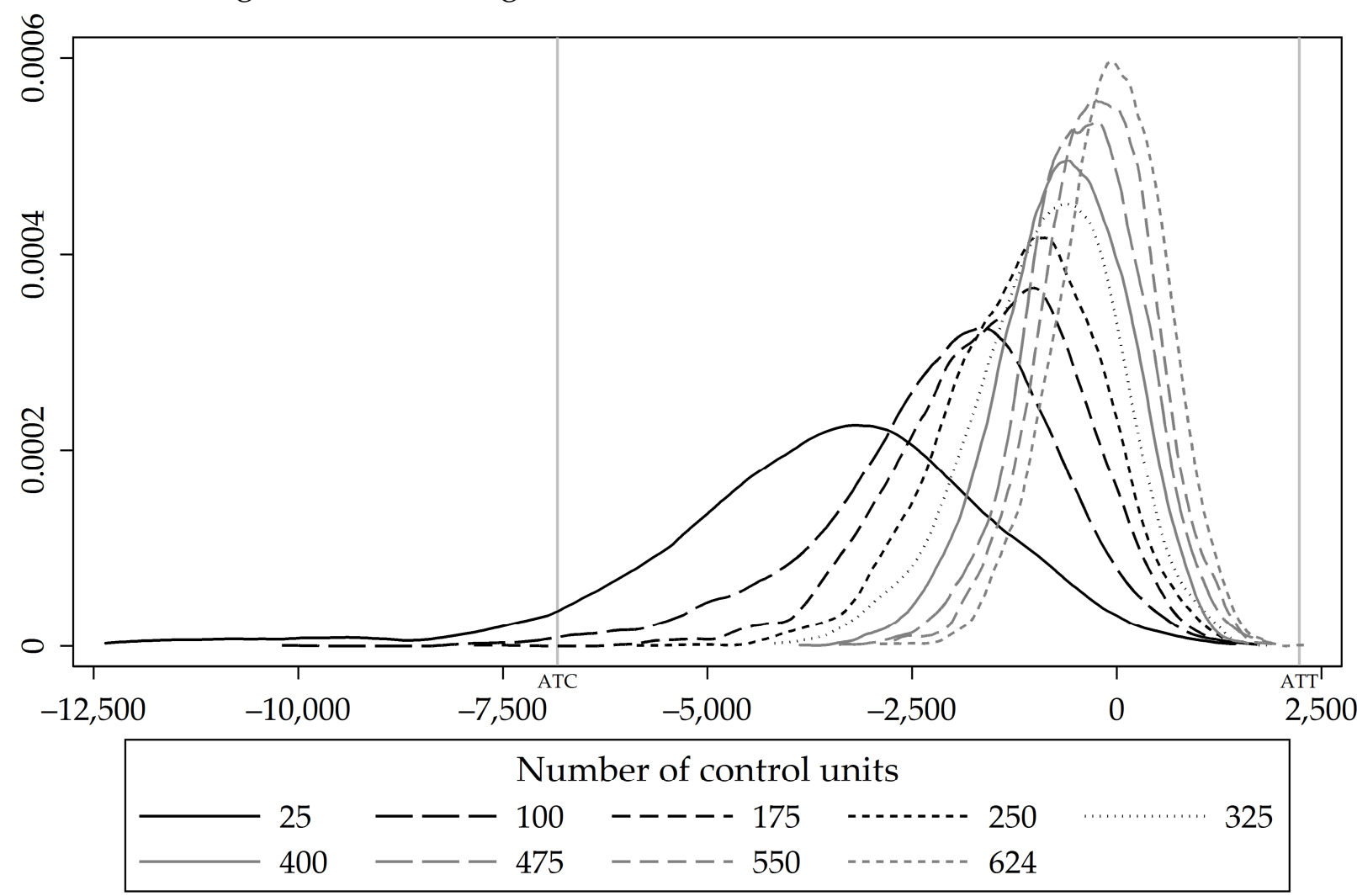

Importantly, I consider nine values of $N_{0}: 25,100,175,250,325,400,475,550$, and 624 . For each $N_{0}$, I draw 2,500 hypothetical samples, and then examine the effects of $N_{0}$ on the finite-sample performance of linear least squares regression.

The results are summarized in Figure 2. ${ }^{9}$ An obvious conclusion is that the higher the proportion of control units, the further we get from the average treatment effect on the controls-and closer to the average treatment effect on the treated. This relationship is monotonic, as previously noted in Corollary 2. Additional results from this simulation study are presented, again, in Appendix C. In particular, Table C9 shows the mean and median bias, the root-mean-square error (RMSE), the median-absolute error (MAE), and the standard deviation of linear least squares regression-separately for each $N_{0}$ and for the estimation of $\tau_{A T T}$ and $\tau_{A T C}$. The conclusions are the same: in terms of bias, RMSE, and MAE, the performance of linear regression in estimating $\tau_{A T T}$ improves with the proportion of control units; similarly, when the proportion of treated units increases, we get closer to $\tau_{A T C}$. Moreover, Table C10 summarizes the empirical distribution of the implicit

\footnotetext{
${ }^{9}$ For clarity, Figure 2 excludes 32 estimates (less than $0.15 \%$ ) which are smaller than $-12,500$.
} 
weights which are used by linear least squares regression to reweight the implied estimates of $\tau_{A T T}$ and $\tau_{A T C}$-again, separately for each $N_{0}$. When the proportion of treated units varies between 0.200 and 0.862 , the average weight on $\hat{\tau}_{A T T}$ varies between 0.638 and 0.368; it is therefore useful to note that-at least in this particular simulation studythe average weights on $\hat{\tau}_{A T T}$ and $\hat{\tau}_{A T C}$ vary somewhat less than the proportions of both groups, but there is also significant variation in weights for each value of $N_{0}$. However, as evident in Table C10, the negative relationship between the proportion of treated (control) units and the implicit weight on $\hat{\tau}_{A T T}\left(\hat{\tau}_{A T C}\right)$ is generally very strong.

\section{Empirical Applications}

This section illustrates the importance of Theorem 1 by means of a replication of two applied papers: Berger et al. (2013) on the effects of CIA interventions during the Cold War on imports from the US; and Martinez-Bravo (2014) on the effects of local officials on electoral results in Indonesia. As noted previously, however, a similar estimation strategy is also used in recent papers by Black et al. (2003), Fryer and Levitt (2004), Gittleman and Wolff (2004), Almond et al. (2005), Elder et al. (2010), Fryer and Greenstone (2010), Fryer and Levitt (2010), Lang and Manove (2011), Alesina et al. (2013), Bond and Lang (2013), Rothstein and Wozny (2013), and many others.

\section{The Effects of US Influence on International Trade (Berger et al., 2013)}

In a recent paper, Berger et al. (2013) provide evidence that successful CIA interventions during the Cold War were used to create a larger foreign market for US-produced goods. The authors use recently declassified CIA documents to construct country- and yearspecific measures of US political influence, and conclude that such influence had a positive effect on the share of total imports that intervened countries purchased from the US. At the same time, however, Berger et al. (2013) find no evidence that CIA interventions increased exports to the US, total imports, or total exports.

In this study, the treatment variable ("CIA intervention" or "US influence") is binary, and equals one whenever-in a given country and year-the CIA either installed a new leader or provided support for the current regime. These activities took various forms, and included "creation and dissemination of (often false) propaganda, ... covert political operations, ... the destruction of physical infrastructure and capital, as well as covert paramilitary operations" (Berger et al., 2013). Apart from the treatment variable, the authors also control for year fixed effects, a Soviet intervention control, ln per capita income, 
Table 1: A Replication of Berger et al. (2013)

\begin{tabular}{|c|c|c|c|c|c|c|}
\hline & $\begin{array}{c}\ln \text { imports } \\
\text { (US) }\end{array}$ & $\begin{array}{c}\ln \text { imports } \\
\text { (US) }\end{array}$ & $\begin{array}{c}\ln \text { imports } \\
\text { (US) }\end{array}$ & $\begin{array}{c}\ln \text { imports } \\
\text { (world) }\end{array}$ & $\begin{array}{c}\ln \text { exports } \\
\text { (US) }\end{array}$ & $\begin{array}{c}\text { ln exports } \\
\text { (world) }\end{array}$ \\
\hline CIA intervention & $\begin{array}{l}0.283^{* *} \\
(0.110)\end{array}$ & $\begin{array}{c}0.776^{* * * *} \\
(0.143)\end{array}$ & $\begin{array}{c}0.293^{* * *} \\
(0.109)\end{array}$ & $\begin{array}{l}-0.009 \\
(0.045)\end{array}$ & $\begin{array}{c}0.058 \\
(0.122)\end{array}$ & $\begin{array}{c}0.000 \\
(0.052)\end{array}$ \\
\hline Country fixed effects & $\checkmark$ & & $\checkmark$ & $\checkmark$ & $\checkmark$ & $\checkmark$ \\
\hline Trade costs and MR controls & & $\checkmark$ & $\checkmark$ & $\checkmark$ & $\checkmark$ & $\checkmark$ \\
\hline Observations & 4,149 & 4,149 & 4,149 & 4,149 & 3,922 & 3,922 \\
\hline
\end{tabular}

Notes: See also Berger et al. (2013) for more details on these data. The unit of observation is a country $c$ in year $t$, where $c$ excludes the US and the Soviet Union and $t$ ranges between 1947 and 1989. The dependent variables are listed in the column headings. Exact definitions of these variables are given in Berger et al. (2013). All regressions include year fixed effects, a Soviet intervention control, ln per capita income, an indicator for leader turnover, current leader tenure, and a democracy indicator. Estimation is based on linear least squares regression. Newey-West standard errors are in parentheses.

*Statistically significant at the $10 \%$ level; **at the $5 \%$ level; ***at the $1 \%$ level.

an indicator for leader turnover, current leader tenure, as well as a democracy indicator. The majority of their baseline specifications also include country fixed effects, trade costs, and Baier-Bergstrand multilateral resistance (MR) terms. The final sample consists of 166 countries, excludes the US and the Soviet Union, and covers the period from 1947 to 1989. Among the 166 countries, 51 experienced a CIA intervention during the Cold War. In a typical year, successful CIA interventions were taking place in 25 countries.

Table 1 reproduces the baseline estimates from Berger et al. (2013). Columns 1-3 report the estimated effects of CIA interventions on imports from the US. All of the coefficients are positive and statistically significant. The estimates from columns 1 and 3 are also very similar in magnitude; the estimate from column 2 is much larger, but this specification excludes country fixed effects. Therefore, Berger et al. (2013) conclude that CIA interventions increased US imports by almost $30 \log$ points (as in columns 1 and 3), and then their remaining specifications control for country fixed effects, trade costs, and MR controls. Further estimates-for different dependent variables-are reported in columns 4-6. All of these coefficients are insignificant and very close to zero. The authors conclude that CIA interventions had no impact on exports to the US, total imports, or total exports.

Perhaps surprisingly, however, the authors interpret their main coefficient of interest as "the average reduced-form impact of CIA interventions on the countries that experience an intervention" (Berger et al., 2013). Unfortunately, this is not a correct interpretation, given their reliance on a model with homogeneous effects which is estimated using ordinary least squares. An interpretation is given, however, in Theorem 1 in this paper: the estimates in Table 1 are all weighted averages of the average effect of CIA interventions on intervened countries (ATT) and the average effect of CIA interventions on 
Table 2: Berger et al. (2013) and Treatment Effect Heterogeneity

\begin{tabular}{|c|c|c|c|c|c|c|}
\hline & $\begin{array}{c}\text { ln imports } \\
\text { (US) }\end{array}$ & $\begin{array}{c}\text { ln imports } \\
\text { (US) }\end{array}$ & $\begin{array}{c}\ln \text { imports } \\
\text { (US) }\end{array}$ & $\begin{array}{c}\text { In imports } \\
\text { (world) }\end{array}$ & $\begin{array}{c}\ln \text { exports } \\
\text { (US) }\end{array}$ & $\begin{array}{c}\text { In exports } \\
\text { (world) }\end{array}$ \\
\hline CIA intervention & $\begin{array}{l}0.283^{* *} \\
(0.110)\end{array}$ & $\begin{array}{c}0.776^{* * *} \\
(0.143)\end{array}$ & $\begin{array}{c}0.293^{* * *} \\
(0.109)\end{array}$ & $\begin{array}{l}-0.009 \\
(0.045)\end{array}$ & $\begin{array}{c}0.058 \\
(0.122)\end{array}$ & $\begin{array}{c}0.000 \\
(0.052)\end{array}$ \\
\hline \multicolumn{7}{|l|}{ Decomposition (Theorem 1) } \\
\hline a. ATT & $\begin{array}{c}0.648^{* * *} \\
(0.138)\end{array}$ & $\begin{array}{c}0.794^{* * *} \\
(0.059)\end{array}$ & $\begin{array}{c}0.717^{* * *} \\
(0.142)\end{array}$ & $\begin{array}{c}0.691^{* * *} \\
(0.150)\end{array}$ & $\begin{array}{c}0.665^{* * *} \\
(0.169)\end{array}$ & $\begin{array}{c}0.863^{* * *} \\
(0.145)\end{array}$ \\
\hline b. $w_{A T T}$ & 0.676 & 0.832 & 0.677 & 0.678 & 0.689 & 0.691 \\
\hline c. ATC & $\begin{array}{c}-0.478^{* * *} \\
(0.144)\end{array}$ & $\begin{array}{c}0.691^{* * *} \\
(0.073)\end{array}$ & $\begin{array}{c}-0.595^{* * *} \\
(0.145)\end{array}$ & $\begin{array}{c}-1.484^{* * *} \\
(0.167)\end{array}$ & $\begin{array}{c}-1.288^{* * *} \\
(0.192)\end{array}$ & $\begin{array}{c}-1.928^{* * *} \\
(0.183)\end{array}$ \\
\hline d. $w_{A T C}$ & 0.324 & 0.168 & 0.323 & 0.322 & 0.311 & 0.309 \\
\hline $\mathrm{OLS}=a \cdot b+c \cdot d$ & $\begin{array}{l}0.283^{* *} \\
(0.110)\end{array}$ & $\begin{array}{c}0.776^{* * *} \\
(0.143)\end{array}$ & $\begin{array}{c}0.293^{* * *} \\
(0.109)\end{array}$ & $\begin{array}{l}-0.009 \\
(0.045)\end{array}$ & $\begin{array}{c}0.058 \\
(0.122)\end{array}$ & $\begin{array}{c}0.000 \\
(0.052)\end{array}$ \\
\hline Country fixed effects & $\checkmark$ & & $\checkmark$ & $\checkmark$ & $\checkmark$ & $\checkmark$ \\
\hline Trade costs and MR controls & & $\checkmark$ & $\checkmark$ & $\checkmark$ & $\checkmark$ & $\checkmark$ \\
\hline Observations & 4,149 & 4,149 & 4,149 & 4,149 & 3,922 & 3,922 \\
\hline $\mathrm{P}(d=1)$ & 0.225 & 0.225 & 0.225 & 0.225 & 0.235 & 0.235 \\
\hline
\end{tabular}

Notes: See also Berger et al. (2013) for more details on these data. The unit of observation is a country $c$ in year $t$, where $c$ excludes the US and the Soviet Union and $t$ ranges between 1947 and 1989. The dependent variables are listed in the column headings. Exact definitions of these variables are given in Berger et al. (2013). All regressions and propensity score specifications include year fixed effects, a Soviet intervention control, ln per capita income, an indicator for leader turnover, current leader tenure, and a democracy indicator. Estimation of "CIA intervention" (=OLS) is based on linear least squares regression. Estimation of ATT and ATC is described in Section 2 (in particular, see Theorem 1). Newey-West standard errors (OLS) and Huber-White standard errors (ATT and ATC) are in parentheses. Huber-White standard errors ignore that the propensity score is estimated.

${ }^{*}$ Statistically significant at the $10 \%$ level; **at the $5 \%$ level; ${ }^{* * *}$ at the $1 \%$ level.

nonintervened countries (ATC), with weights which are perhaps poorly chosen. At the same time, it is certainly very convincing to follow the intention of the authors, and focus on the average effect on intervened countries. This parameter can be used to answer the question about the actual consequences of CIA interventions during the Cold War. It is less useful to estimate the effect of CIA interventions on countries, in which interventions were highly unlikely, such as Australia, Canada, or the United Kingdom. Therefore, the average effect on nonintervened countries is arguably of little interest in this application, and I focus on the average effect on the "treated".

Table 2 decomposes the baseline estimates from Berger et al. (2013) into two components, the average effect of CIA interventions on intervened countries (ATT) and the average effect of CIA interventions on nonintervened countries (ATC). It also reports the implicit weights on these estimates. First, it is useful to note that about $23 \%$ of the units are treated, but at the same time the weight on $\hat{\tau}_{A T T}$ varies between 0.676 and 0.832 . Sec- 
ond, the implied estimates of the average effect of CIA interventions on intervened countries are all positive, statistically significant, and very similar in magnitude. These estimates suggest that CIA interventions influenced all measures of international trade, and increased US imports, US exports, total imports, and total exports by $65-86$ log points. Therefore, the large discrepancies in the estimates reported in Table 1-and the main conclusion in Berger et al. (2013) - are driven by the large variation in the effect on nonintervened countries across specifications. This is easily visible in Table 2, where $\hat{\tau}_{A T C}$ varies between -1.928 and 0.691 , and hence we get the reported variation in the OLS estimate. Whenever $\hat{\tau}_{A T C}$ is negative and relatively large in absolute value (columns 4-6), the weighted average of $\hat{\tau}_{A T C}$ and $\hat{\tau}_{A T T}$ is approximately zero. Whenever $\hat{\tau}_{A T C}$ is relatively close to zero (columns 1-3), this weighted average becomes significantly positive.

Still, the following question arises: did CIA interventions really increase international trade in intervened countries by 65-86 log points? The magnitude of this effect is arguably difficult to believe, and we need to recall that these estimates are based on an estimator which is likely to perform very poorly in finite samples (see Section 3). More precisely, this method involves two steps: in the first step, calculate the "propensity score" from the linear probability model; in the second step, calculate average partial effects from a model which assumes a linear relationship between potential outcomes and this "propensity score". This second linearity assumption is particularly restrictive, and therefore we might need an additional robustness check.

Table 3 reports further estimates of the effects of CIA interventions on various measures of international trade. Before estimating these effects, I improve overlap by discarding observations whose propensity score is less than the minimum or greater than the maximum propensity score for the other group (intervened or nonintervened countries). Then, I recalculate the OLS estimates as well as provide nearest-neighbor matching estimates of the average effect of CIA interventions on intervened countries. I consider two alternative models for the propensity score: a linear probability model and a probit model ("ATT-LPM" and "ATT-probit"). In the first case, I simply retain the estimates of the "propensity score" which are implied by OLS. In other words, I relax a restrictive assumption from the second stage of the previous two-step procedure, but retain the first stage. As evident in Table 3, improving overlap does not significantly alter the OLS estimates (compared with Table 1). At the same time, the OLS estimates are not robust to relaxing the linearity assumption. The majority of the matching estimates ("ATT-LPM") become negative and statistically significant.

In the second case, I use a probit model for the propensity score, but also implement an additional refinement of the matching procedure-namely, a requirement of exact match- 
Table 3: Further Estimates of the Effects of US Influence on International Trade (Overlap Sample)

\begin{tabular}{|c|c|c|c|c|c|c|}
\hline & $\begin{array}{c}\text { ln imports } \\
\text { (US) }\end{array}$ & $\begin{array}{l}\text { ln imports } \\
\text { (US) }\end{array}$ & $\begin{array}{l}\text { ln imports } \\
\text { (US) }\end{array}$ & $\begin{array}{l}\text { ln imports } \\
\text { (world) }\end{array}$ & $\begin{array}{l}\text { ln exports } \\
\text { (US) }\end{array}$ & $\begin{array}{l}\text { ln exports } \\
\text { (world) }\end{array}$ \\
\hline OLS & $\begin{array}{l}0.307^{* * *} \\
(0.106)\end{array}$ & $\begin{array}{l}0.761^{* * *} \\
(0.144)\end{array}$ & $\begin{array}{l}0.315^{* * *} \\
(0.106)\end{array}$ & $\begin{array}{l}-0.023 \\
(0.042)\end{array}$ & $\begin{array}{c}0.064 \\
(0.124)\end{array}$ & $\begin{array}{l}-0.000 \\
(0.055)\end{array}$ \\
\hline Observations & 3,154 & 4,105 & 3,111 & 2,669 & 2,455 & 2,505 \\
\hline ATT-LPM & $\begin{array}{l}-0.535^{*} \\
(0.308)\end{array}$ & $\begin{array}{l}0.783^{* * *} \\
(0.086)\end{array}$ & $\begin{array}{l}-0.615^{* *} \\
(0.290)\end{array}$ & $\begin{array}{l}-0.664^{* *} \\
(0.320)\end{array}$ & $\begin{array}{l}-0.702^{*} \\
(0.377)\end{array}$ & $\begin{array}{l}-0.690^{* *} \\
(0.272)\end{array}$ \\
\hline Observations & 3,154 & 4,105 & 3,111 & 2,669 & 2,455 & 2,505 \\
\hline ATT-probit & $\begin{array}{c}0.027 \\
(0.197)\end{array}$ & $\begin{array}{l}-0.084 \\
(0.185)\end{array}$ & $\begin{array}{c}0.007 \\
(0.197)\end{array}$ & $\begin{array}{l}-0.385^{*} \\
(0.219)\end{array}$ & $\begin{array}{l}-0.126 \\
(0.261)\end{array}$ & $\begin{array}{l}-0.288 \\
(0.227)\end{array}$ \\
\hline Observations & 1,182 & 1,398 & 1,102 & 1,085 & 978 & 982 \\
\hline $\begin{array}{l}\text { Country fixed effects } \\
\text { Trade costs and MR controls }\end{array}$ & $\checkmark$ & $\checkmark$ & $\begin{array}{l}\checkmark \\
\checkmark\end{array}$ & $\begin{array}{l}\checkmark \\
\checkmark\end{array}$ & $\begin{array}{l}\checkmark \\
\checkmark\end{array}$ & $\begin{array}{l}\checkmark \\
\checkmark\end{array}$ \\
\hline
\end{tabular}

Notes: See also Berger et al. (2013) for more details on these data. The unit of observation is a country $c$ in year $t$, where $c$ excludes the US and the Soviet Union and $t$ ranges between 1947 and 1989. The dependent variables are listed in the column headings. Exact definitions of these variables are given in Berger et al. (2013). All regressions and propensity score specifications include year fixed effects, a Soviet intervention control, ln per capita income, an indicator for leader turnover, current leader tenure, and a democracy indicator. For "OLS", estimation is based on linear least squares regression. For "ATT-LPM" and "ATT-probit", estimation is based on nearest-neighbor matching on the estimated propensity score (with a single match). For "ATT-probit", exact matching on $c$ is also required. The propensity score is estimated using a linear probability model ("ATT-LPM") or a probit model ("ATT-probit"). Newey-West standard errors (OLS) and Abadie-Imbens standard errors (ATT) are in parentheses. Abadie-Imbens standard errors ignore that the propensity score is estimated.

*Statistically significant at the $10 \%$ level; **at the $5 \%$ level; ***at the $1 \%$ level.

ing within each country. As evident in Table 3, again, the estimates are not robust to this change in the procedure. Columns 1-3 report the estimated effects of CIA interventions on US imports. All of these estimates are insignificant and close to zero. Similarly, the estimated effects on US exports and total exports-although larger in magnitude-are also insignificant (columns 5 and 6). Only the estimated effect on total imports is negative, statistically significant, and again larger in magnitude (column 4). These results lead to an alternative interpretation of these data: CIA interventions either did not influence international trade in intervened countries or might have had a small and negative effect, perhaps by means of destabilizing these countries and their economies. At the same time, the estimated effects on US imports are much smaller in magnitude than the effects on total imports. Presumably, successful CIA interventions during the Cold War were indeed used to determine international trade in intervened countries-and counterbalance the negative effects of these interventions on US imports-but the pattern of these effects is likely to be different from the interpretation in Berger et al. (2013). 


\section{The Effects of Local Officials on Electoral Results (Martinez-Bravo, 2014)}

A recent paper by Martinez-Bravo (2014) examines the differences in behavior between appointed and elected officials. In particular, the author focuses on the 1999 parliamentary election in Indonesia, i.e. on the first democratic election in this country after the fall of the Soeharto regime, and compares the electoral results in kelurahan and in desa villages (which have appointed and elected heads, respectively). She concludes that Golkar, i.e. Soeharto's party, was significantly more likely to win in kelurahan than in desa villages, and hence that "the body of appointed officials ... is a key determinant of the extent of electoral fraud and clientelistic spending in new democracies" (Martinez-Bravo, 2014).

The treatment variable is again binary-and equals one for kelurahan villages. The sample consists of 43,394 villages, of which 3,036 (7\%) are kelurahan and 40,358 (93\%) are desa. The outcome variable is also binary, and equals one if Golkar was the most voted party in the village; in some cases-though not in the baseline specifications-there is an alternative outcome variable, which equals one if PDI-P (a competing party and the winner of the 1999 election) was the most voted party in this village. The majority of specifications also include district (kabupaten) fixed effects, and many specifications control for various geographical characteristics of the villages as well as for the availability of religious, health, and educational facilities.

It is important to note that Martinez-Bravo (2014) does not specify whether her intention is to estimate the average effect of appointed officials (ATE) or the average effect of appointed officials on kelurahan villages (ATT). Both of these parameters are potentially interesting, although the former is presumably more in line with one of the main objectives of Martinez-Bravo (2014), i.e. testing for (average) differences in behavior between appointed and elected officials. The latter parameter would be more relevant if our intention was to examine the actual impact of appointed officials on the electoral outcome. Therefore, in this section, I focus on the average treatment effect, but discuss various estimates of both this parameter and the average effect on the "treated".

Recall, however, that neither of these parameters is recovered by linear least squares regression, while this is the primary estimation method used by Martinez-Bravo (2014). The author also uses a probit model and a particular method based on the propensity score, and all these methods seem to give similar answers. However, quite unexpectedly, this particular propensity-score method_used by Martinez-Bravo (2014)_is implicitly based on the assumption of homogeneity in effects; it is in fact equivalent to a variant of linear least squares regression with a different set of control variables. More precisely, this

method involves three steps: in the first step, the author estimates the propensity score using an algorithm based on a probit model; in the second step, she imposes the over- 
Table 4: A Replication of Martinez-Bravo (2014)

\begin{tabular}{|c|c|c|c|c|c|c|c|c|}
\hline & \multicolumn{5}{|c|}{ Linear probability model } & \multicolumn{3}{|c|}{ Propensity score model } \\
\hline & (1) & (2) & (3) & (4) & (5) & (6) & (7) & (8) \\
\hline Kelurahan indicator & $\begin{array}{c}0.074^{* * *} \\
(0.028)\end{array}$ & $\begin{array}{c}0.006 \\
(0.012)\end{array}$ & $\begin{array}{c}0.057^{* * * *} \\
(0.012)\end{array}$ & $\begin{array}{c}0.057^{* * *} \\
(0.012)\end{array}$ & $\begin{array}{c}0.055^{* * *} \\
(0.012)\end{array}$ & $\begin{array}{c}0.023^{* * *} \\
(0.008)\end{array}$ & $\begin{array}{c}0.030^{* * *} \\
(0.009)\end{array}$ & $\begin{array}{c}0.033^{* * *} \\
(0.008)\end{array}$ \\
\hline Geographic controls & & & $\checkmark$ & $\checkmark$ & $\checkmark$ & $\checkmark$ & $\checkmark$ & $\checkmark$ \\
\hline Religious controls & & & & $\checkmark$ & $\checkmark$ & & $\checkmark$ & $\checkmark$ \\
\hline Facilities controls & & & & & $\checkmark$ & & & $\checkmark$ \\
\hline District fixed effects & & $\checkmark$ & $\checkmark$ & $\checkmark$ & $\checkmark$ & $\checkmark$ & $\checkmark$ & $\checkmark$ \\
\hline Observations & 43,394 & 43,394 & 43,394 & 43,394 & 43,394 & 21,502 & 20,565 & 19,206 \\
\hline
\end{tabular}

Notes: See also Martinez-Bravo (2014) for more details on these data. The unit of observation is a village. The dependent variable equals one if Golkar was the most voted party in the village in the 1999 parliamentary election and zero otherwise. Geographic controls include population density, a quartic in the logarithm of the village population, a quartic in the percentage of households whose main occupation is in agriculture, share of agricultural land in the village, distance to the subdistrict office, distance to the district capital, and indicators for urban and high altitude. Religious controls include the number of mosques, prayer houses, churches, and Buddhist temples per 1,000 people. Facilities controls include the number of hospitals, maternity hospitals, polyclinics, puskesmas (primary care centers), kindergartens, primary schools, high schools, and TVs per 1,000 people. Estimation is based on linear least squares regression, with controls for either the variables listed in the table (columns 1-5) or the propensity-score strata, province fixed effects, and the full set of interactions between the strata and the fixed effects (columns 6-8). In the latter case, the variables listed in the table correspond to the propensity score specifications. Cluster-robust standard errors (columns 1-5) and bootstrap standard errors (columns 6-8) are in parentheses.

*Statistically significant at the $10 \%$ level; **at the $5 \%$ level; ***at the $1 \%$ level.

lap condition, calculates quintiles of the distribution of the estimated propensity score, and uses them to generate five propensity-score strata; in the third step, she runs the regression of the dependent variable on the kelurahan indicator, province fixed effects, five indicator variables for the strata, and the full set of interactions between the strata and the fixed effects. Because this last regression does not include interactions between the control variables and the treatment variable, Martinez-Bravo (2014) implicitly makes the assumption of treatment effect homogeneity (both within and between the strata).

Consequently, Table 4 reproduces the baseline estimates from Martinez-Bravo (2014), both for the linear probability model and for the propensity score model. There are large differences between the coefficients in column 1 and 2 as well as between column 2 and 3 . However, when geographic controls are included in column 3, the estimated effect stabilizes, and suggests that appointed officials increased the probability of Golkar victory by 6 percentage points (columns 3-5) or 2-3 percentage points (columns 6-8). All of these coefficients are statistically significant and also very similar in magnitude within each of the estimation methods.

Table 5 applies the main theoretical result of this paper to these estimates, and decomposes all the baseline coefficients from Martinez-Bravo (2014) into two components, the 
Table 5: Martinez-Bravo (2014) and Treatment Effect Heterogeneity

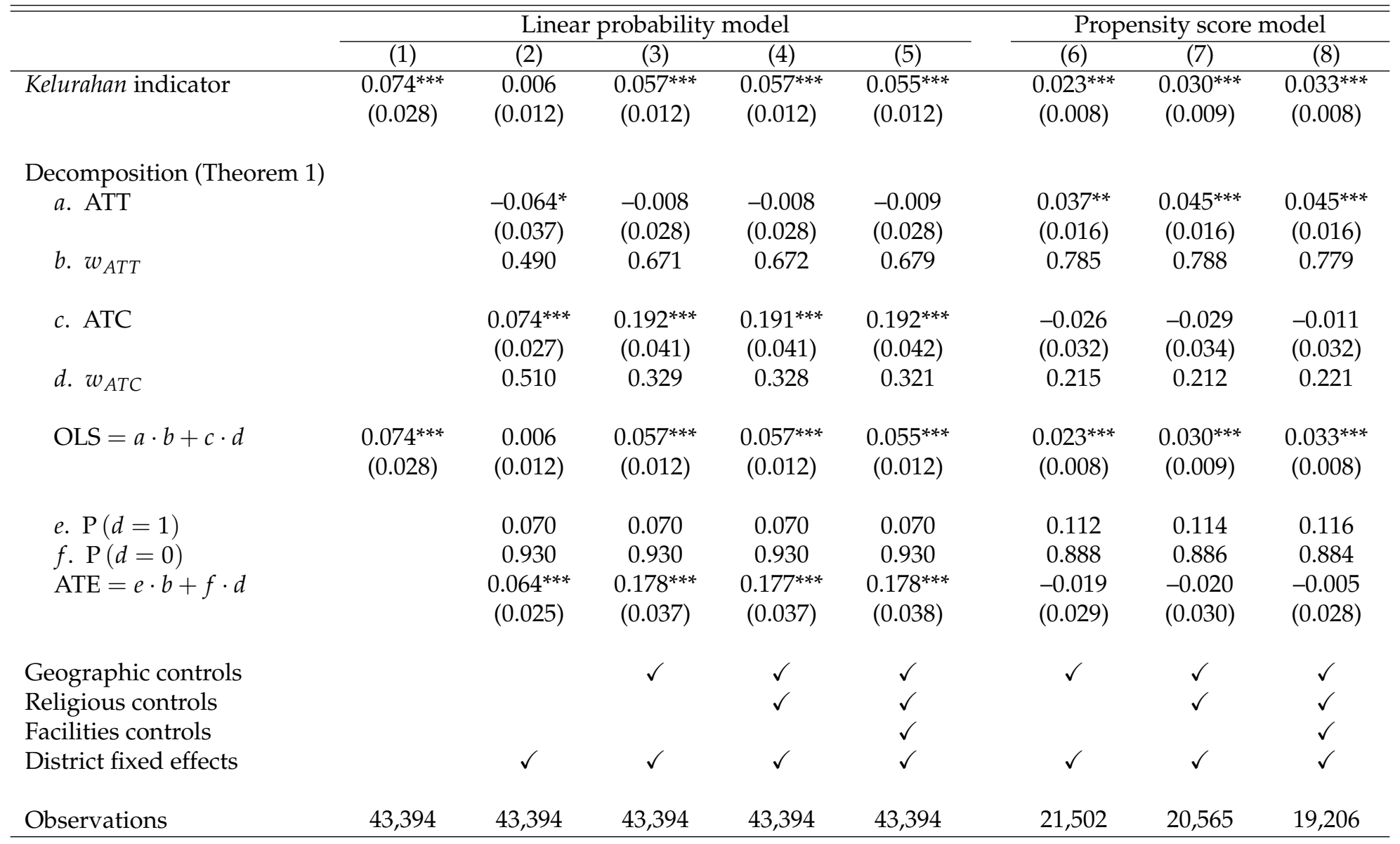

Notes: See also Martinez-Bravo (2014) for more details on these data. The unit of observation is a village. The dependent variable equals one if Golkar was the most voted party in the village in the 1999 parliamentary election and zero otherwise. Geographic controls include population density, a quartic in the logarithm of the village population, a quartic in the percentage of households whose main occupation is in agriculture, share of agricultural land in the village, distance to the subdistrict office, distance to the district capital, and indicators for urban and high altitude. Religious controls include the number of mosques, prayer houses, churches, and Buddhist temples per 1,000 people. Facilities controls include the number of hospitals, maternity hospitals, polyclinics, puskesmas (primary care centers), kindergartens, primary schools, high schools, and TVs per 1,000 people. Estimation of "Kelurahan indicator" (=OLS) is based on linear least squares regression, with controls for either the variables listed in the table (columns 1-5) or the propensity-score strata, province fixed effects, and the full set of interactions between the strata and the fixed effects (columns 6-8). In the latter case, the variables listed in the table correspond to the propensity score specifications. Estimation of ATT and ATC is described in Section 2 (in particular, see Theorem 1). Cluster-robust standard errors (columns 1-5, OLS), bootstrap standard errors (columns 6-8, OLS), and Huber-White standard errors (ATT, ATC, and ATE) are in parentheses. Huber-White standard errors ignore that the propensity score is estimated.

*Statistically significant at the $10 \%$ level; **at the $5 \%$ level; *** at the $1 \%$ level.

average effect of appointed officials on kelurahan villages (ATT) and the average effect of appointed officials on desa villages (ATC). I also report the implicit weights which are used by linear regression to reweight both of these estimates. While the proportion of kelurahan villages varies between $7 \%$ and $12 \%$, the weight on $\hat{\tau}_{A T T}$ varies between 0.490 and 0.788. Because-in this empirical context—we should arguably intend to estimate 
the average treatment effect, I also report a "properly reweighted" weighted average of $\hat{\tau}_{A T T}$ and $\hat{\tau}_{A T C}$, i.e. an estimate of the average effect of appointed officials (ATE). Since the weights underlying linear regression are poorly chosen, we can expect large differences between these estimates and the OLS estimates, and this is indeed the case. The results of the decompositions in Table 5 are generally quite surprising, and they differ enormously between the linear probability model and the propensity score model. In the case of the linear probability model, all of the implied estimates of the average treatment effect are positive and statistically significant. The estimates from columns 3-5 are also very similar in magnitude, and they suggest that-on average-appointed officials increased the probability of Golkar victory by 18 percentage points. At the same time, however, the implied estimates of the average effect on kelurahan villages are close to zero and usually insignificant. When we turn to the results from the propensity score model-which are obtained for the overlap sample-this pattern is reversed. The average effect of appointed officials on kelurahan villages seems to be relatively small in absolute value, but positive and significant; the average treatment effect is indistinguishable from zero.

Which of these patterns is believable? Is the average effect of appointed officials positive, but the average effect on kelurahan villages close to zero? Or, maybe the appointed officials increased the probability of Golkar victory only in the "treated" villages? Again, we might try to reconcile these conflicting findings using an alternative estimation method. Therefore, Table 6 reports further OLS and nearest-neighbor matching estimates of the effects of appointed officials on electoral results in Indonesia-all of which are obtained for the overlap sample (as defined in Martinez-Bravo, 2014). The OLS estimates do not change in a substantial way. The propensity score-used in matching-is estimated either using a linear probability model (as, implicitly, in Table 5) or using a specific algorithm based on a probit model (as, explicitly, in Martinez-Bravo, 2014). In the latter case, I also impose a requirement of exact matching within each province. As evident in Table 6, the average effect on the "treated" seems to be positive and statistically significant regardless of the matching procedure; if we ignore column 2, the estimated effects vary between 3 and 7 percentage points. However, when we turn to the average effect of appointed officials, these procedures lead to substantially different conclusions. In line with the results in Martinez-Bravo (2014), the average effect of appointed officials is significantly positive-but only if the propensity score is estimated using a linear probability model. If, however, we prefer a probit model and-especially-exact matching within each province, then all of the estimates are insignificant and very close to zero. Perhaps the average difference in electoral results between similar kelurahan and desa villages is indeed negligible. If this conclusion is correct, it casts doubt on one of the main results 
Table 6: Further Estimates of the Effects of Local Officials on Electoral Results (Overlap Sample)

\begin{tabular}{|c|c|c|c|c|c|c|c|c|}
\hline & \multicolumn{5}{|c|}{ Linear probability model } & \multicolumn{3}{|c|}{ Probit model } \\
\hline & (1) & (2) & (3) & (4) & (5) & (6) & (7) & (8) \\
\hline \multirow{2}{*}{ OLS } & - & 0.006 & $0.033^{* * *}$ & $0.033^{* * *}$ & $0.035^{\text {***}}$ & $0.023^{\star * *}$ & $0.030^{* * *}$ & $0.033^{* * *}$ \\
\hline & & $(0.012)$ & $(0.011)$ & $(0.011)$ & $(0.011)$ & $(0.008)$ & $(0.009)$ & $(0.008)$ \\
\hline \multirow[t]{2}{*}{ ATT } & - & 0.007 & $0.032^{*}$ & $0.069^{* * *}$ & $0.036^{*}$ & $0.028^{*}$ & $0.030^{*}$ & $0.031^{*}$ \\
\hline & & $(0.008)$ & $(0.019)$ & $(0.019)$ & $(0.020)$ & $(0.016)$ & $(0.016)$ & $(0.016)$ \\
\hline \multirow[t]{2}{*}{ ATE } & - & 0.003 & $0.085^{* * *}$ & $0.117^{* * *}$ & $0.097^{* * *}$ & -0.005 & -0.007 & -0.001 \\
\hline & & $(0.010)$ & $(0.029)$ & $(0.029)$ & $(0.033)$ & $(0.030)$ & $(0.031)$ & $(0.031)$ \\
\hline Geographic controls & & & $\checkmark$ & $\checkmark$ & $\checkmark$ & $\checkmark$ & $\checkmark$ & $\checkmark$ \\
\hline Religious controls & & & & $\checkmark$ & $\checkmark$ & & $\checkmark$ & $\checkmark$ \\
\hline Facilities controls & & & & & $\checkmark$ & & & $\checkmark$ \\
\hline District fixed effects & & $\checkmark$ & $\checkmark$ & $\checkmark$ & $\checkmark$ & $\checkmark$ & $\checkmark$ & $\checkmark$ \\
\hline Observations & 43,394 & 43,394 & 21,502 & 20,565 & 19,206 & 21,502 & 20,565 & 19,206 \\
\hline
\end{tabular}

Notes: See also Martinez-Bravo (2014) for more details on these data. The unit of observation is a village. The dependent variable equals one if Golkar was the most voted party in the village in the 1999 parliamentary election and zero otherwise. Geographic controls include population density, a quartic in the logarithm of the village population, a quartic in the percentage of households whose main occupation is in agriculture, share of agricultural land in the village, distance to the subdistrict office, distance to the district capital, and indicators for urban and high altitude. Religious controls include the number of mosques, prayer houses, churches, and Buddhist temples per 1,000 people. Facilities controls include the number of hospitals, maternity hospitals, polyclinics, puskesmas (primary care centers), kindergartens, primary schools, high schools, and TVs per 1,000 people. For "OLS", estimation is based on linear least squares regression, with controls for either the variables listed in the table (columns 1-5) or the propensity-score strata, province fixed effects, and the full set of interactions between the strata and the fixed effects (columns 6-8). In the latter case, the variables listed in the table correspond to the propensity score specifications. For "ATT" and "ATE", estimation is based on nearest-neighbor matching on the estimated propensity score (with a single match). For columns 6-8, exact matching on province fixed effects is also required. The propensity score is estimated using a linear probability model (columns 1-5) or an algorithm based on a probit model (columns 6-8). A description of this algorithm is given in Martinez-Bravo (2014). Cluster-robust standard errors (columns 1-5, OLS), bootstrap standard errors (columns 6-8, OLS), and Abadie-Imbens standard errors (ATT and ATE) are in parentheses. Abadie-Imbens standard errors ignore that the propensity score is estimated.

*Statistically significant at the $10 \%$ level; ${ }^{* *}$ at the $5 \%$ level; ***at the $1 \%$ level.

in Martinez-Bravo (2014) — that the behavior of appointed and elected officials is, on average, very different. ${ }^{10}$

\footnotetext{
${ }^{10}$ Another conclusion in Martinez-Bravo (2014) is that the effect of appointed officials should be stronger in districts, in which Golkar was expected to win by a large margin, because such expectations incentivize these officials to manifest their allegiance to the regime. Also, the effect should be reversed in districts, in which PDI-P was expected to win by a large margin. These conclusions are tested in Appendix D, where various models are estimated on subsamples of the original data-and these subsamples are defined on the basis of district-level electoral results (PDI-P won large, PDI-P just won, Golkar just won, Golkar won large). Table D11 and Table D12 replicate the estimates from Martinez-Bravo (2014). Table D13 and Table D14 apply the main theoretical result of this paper to these estimates, and decompose all the coefficients from Table D11 and Table D12 into two components (ATT and ATC). Many of the results change. Table D15 and Table D16 present further OLS estimates as well as nearest-neighbor matching estimates of the average effect of appointed officials and of the average effect of appointed officials on kelurahan villages (for the overlap sample). If we prefer the probit-based estimates of the propensity score and exact matching within each province, then this conclusion in Martinez-Bravo (2014) is correct for the effect of local officials on Golkar victory - this effect is positive and significant only for districts, in which Golkar won by a large
} 


\section{Summary}

In this paper I study the interpretation of the least squares estimand in the homogeneous linear model when treatment effects are in fact heterogeneous. This problem is highly relevant for empirical economists, because many influential papers rely on linear least squares regression to provide estimates of the effects of various treatments, while treatment effect heterogeneity is often empirically important. How should we interpret the estimates in these studies? I derive a new theoretical result which demonstrates that linear least squares regression is equivalent to a weighted average of two estimators, both of which are likely to perform poorly in finite samples, with weights which are also poorly chosen. In particular, the weight which is placed by linear regression on the average effect on each group (treated or controls) is inversely related to the proportion of this group. The more units get treatment, the less weight is placed on the average treatment effect on the treated. I also illustrate the importance of this result with two Monte Carlo studies, as well as with a replication of two prominent applied papers: Berger et al. (2013) on the effects of CIA interventions on international trade; and Martinez-Bravo (2014) on the effects of appointed officials on electoral outcomes. In both cases some important conclusions are not robust to allowing for heterogeneity in effects.

There are several lessons to be learned from this paper. First, empirical economists often believe that linear least squares regression provides a good approximation to the average treatment effect. Some authors only give their attention to issues of heterogeneity if this is motivated by a theoretical model or previous literature. However, linear least squares regression might provide biased estimates of each of the relevant parameters of interest whenever heterogeneity is empirically important. Sometimes, of course, this bias might be small, but this should never be taken for granted.

Second, it is useful to test for treatment effect heterogeneity. The main result of this paper (Theorem 1) provides a directly applicable decomposition for every least squares estimate, which can now be represented as a weighted average of two particular estimates: of the average treatment effect on the treated and of the average treatment effect on the controls. This decomposition can be applied as an easy-to-use informal test for treatment effect heterogeneity. However, more sophisticated procedures have also been developed, and can be used (see, e.g., Crump, Hotz, Imbens and Mitnik, 2008).

Finally, it is essential to always define the parameter of interest. Many empirical papers lack a clear statement about the actual goal of the researcher-whether they are inter-

margin, and this includes the average treatment effect. However, when we turn to the effect on PDI-P victory, neither of the estimated effects is significantly different from zero-and they are usually very small. 
ested in the average effect, the average effect on some clearly defined population, or some other parameter. The linear regression estimand is seldom the most interesting parameter per se, and it might not correspond to any of the relevant parameters, as this paper also clarifies. Defining the parameter of interest is important, because it enables the researcher to provide an interpretation of their result, and it also guarantees comparability between estimation methods. In some cases a precise definition of the parameter of interest might even allow the researcher to continue using linear least squares regression: as this paper clarifies, if nearly nobody gets treatment and we are interested in the effect on the treated, then we can maintain that we are approximately correct. 


\section{A Proofs}

Proof of Theorem 1. First, consider equation (4), $\mathrm{L}(y \mid 1, d, X)=\alpha+\tau d+X \beta$. By the Frisch-Waugh theorem (Frisch and Waugh, 1933), $\tau=\tau_{a}$, where $\tau_{a}$ is defined by

$$
\mathrm{L}[y \mid 1, d, p(X)]=\alpha_{a}+\tau_{a} d+\gamma_{a} \cdot p(X) .
$$

Second, notice that (14) is a linear projection of $y$ on two variables: one binary and one continuous. We can therefore use the following result from Elder et al. (2010):

Lemma 1 (Elder et al., 2010) Let $\mathrm{L}(y \mid 1, d, x)=\alpha_{e}+\tau_{e} d+\beta_{e} x$ denote the linear projection of $y$ on $d$ (a binary variable) and $x$ (a single, possibly continuous, control variable) and let $\mathrm{V}(\cdot)$, $\operatorname{Cov}(\cdot), \mathrm{V}(\cdot \mid \cdot)$, and $\operatorname{Cov}(\cdot \mid \cdot)$ denote the variance, the covariance, the conditional variance, and the conditional covariance, respectively. Then,

$$
\begin{aligned}
\tau_{e} & =\frac{\rho \cdot \mathrm{V}(x \mid d=1)}{\rho \cdot \mathrm{V}(x \mid d=1)+(1-\rho) \cdot \mathrm{V}(x \mid d=0)} \cdot w_{1} \\
& +\frac{(1-\rho) \cdot \mathrm{V}(x \mid d=0)}{\rho \cdot \mathrm{V}(x \mid d=1)+(1-\rho) \cdot \mathrm{V}(x \mid d=0)} \cdot w_{0}
\end{aligned}
$$

where

$$
w_{1}=\frac{\operatorname{Cov}(d, y)}{\mathrm{V}(d)}-\frac{\operatorname{Cov}(d, x)}{\mathrm{V}(d)} \cdot \frac{\operatorname{Cov}(x, y \mid d=1)}{\mathrm{V}(x \mid d=1)}
$$

and

$$
w_{0}=\frac{\operatorname{Cov}(d, y)}{\mathrm{V}(d)}-\frac{\operatorname{Cov}(d, x)}{\mathrm{V}(d)} \cdot \frac{\operatorname{Cov}(x, y \mid d=0)}{\mathrm{V}(x \mid d=0)} .
$$

Combining the two pieces gives

$$
\begin{aligned}
\tau & =\frac{\rho \cdot \mathrm{V}[p(X) \mid d=1]}{\rho \cdot \mathrm{V}[p(X) \mid d=1]+(1-\rho) \cdot \mathrm{V}[p(X) \mid d=0]} \cdot w_{1}^{*} \\
& +\frac{(1-\rho) \cdot \mathrm{V}[p(X) \mid d=0]}{\rho \cdot \mathrm{V}[p(X) \mid d=1]+(1-\rho) \cdot \mathrm{V}[p(X) \mid d=0]} \cdot w_{0}^{*},
\end{aligned}
$$

where

$$
w_{1}^{*}=\frac{\operatorname{Cov}(d, y)}{\mathrm{V}(d)}-\frac{\operatorname{Cov}[d, p(X)]}{\mathrm{V}(d)} \cdot \frac{\operatorname{Cov}[p(X), y \mid d=1]}{\mathrm{V}[p(X) \mid d=1]}
$$

and

$$
w_{0}^{*}=\frac{\operatorname{Cov}(d, y)}{\mathrm{V}(d)}-\frac{\operatorname{Cov}[d, p(X)]}{\mathrm{V}(d)} \cdot \frac{\operatorname{Cov}[p(X), y \mid d=0]}{\mathrm{V}[p(X) \mid d=0]}
$$


Third, notice that $w_{1}^{*}=\tau_{A P E \mid d=0}$ and $w_{0}^{*}=\tau_{A P E \mid d=1}$, as defined in (10). Indeed,

$$
\frac{\operatorname{Cov}(d, y)}{\mathrm{V}(d)}=\mathrm{E}(y \mid d=1)-\mathrm{E}(y \mid d=0)
$$

and also

$$
\frac{\operatorname{Cov}[d, p(X)]}{\mathrm{V}(d)}=\mathrm{E}[p(X) \mid d=1]-\mathrm{E}[p(X) \mid d=0] .
$$

Moreover, for $j=0,1$,

$$
\frac{\operatorname{Cov}[p(X), y \mid d=j]}{\mathrm{V}[p(X) \mid d=j]}=\gamma_{j}
$$

where $\gamma_{1}$ and $\gamma_{0}$ are defined in (7) and (8), respectively. Because

$$
\begin{aligned}
\mathrm{E}(y \mid d=1)-\mathrm{E}(y \mid d=0) & =\{\mathrm{E}[p(X) \mid d=1]-\mathrm{E}[p(X) \mid d=0]\} \cdot \gamma_{1} \\
& +\left(\alpha_{1}-\alpha_{0}\right)+\left(\gamma_{1}-\gamma_{0}\right) \cdot \mathrm{E}[p(X) \mid d=0]
\end{aligned}
$$

and also

$$
\begin{aligned}
\mathrm{E}(y \mid d=1)-\mathrm{E}(y \mid d=0) & =\{\mathrm{E}[p(X) \mid d=1]-\mathrm{E}[p(X) \mid d=0]\} \cdot \gamma_{0} \\
& +\left(\alpha_{1}-\alpha_{0}\right)+\left(\gamma_{1}-\gamma_{0}\right) \cdot \mathrm{E}[p(X) \mid d=1]
\end{aligned}
$$

where again $\alpha_{1}$ and $\alpha_{0}$ are defined in (7) and (8), we get the result that $w_{1}^{*}=\tau_{A P E \mid d=0}$ and $w_{0}^{*}=\tau_{A P E \mid d=1}$. Interestingly, equations (21) and (22) are special cases of the OaxacaBlinder decomposition (Blinder, 1973; Oaxaca, 1973; Fortin, Lemieux and Firpo, 2011).

Combining the three pieces gives

$$
\begin{aligned}
\tau & =\frac{\rho \cdot \mathrm{V}[p(X) \mid d=1]}{\rho \cdot \mathrm{V}[p(X) \mid d=1]+(1-\rho) \cdot \mathrm{V}[p(X) \mid d=0]} \cdot \tau_{A P E \mid d=0} \\
& +\frac{(1-\rho) \cdot \mathrm{V}[p(X) \mid d=0]}{\rho \cdot \mathrm{V}[p(X) \mid d=1]+(1-\rho) \cdot \mathrm{V}[p(X) \mid d=0]} \cdot \tau_{A P E \mid d=1}
\end{aligned}
$$

which completes the proof. 


\section{B The Relationship between Theorem 1 and Angrist (1998)}

Note that Angrist (1998) considers a model with two strata, where $x$ (a binary variable) indicates stratum membership. His result is that if $L(y \mid 1, d, x)=\alpha_{n}+\tau_{n} d+\beta_{n} x$, then

$$
\begin{aligned}
\tau_{n} & =\frac{\mathrm{P}(x=0) \cdot \mathrm{V}(d \mid x=0)}{\mathrm{P}(x=0) \cdot \mathrm{V}(d \mid x=0)+\mathrm{P}(x=1) \cdot \mathrm{V}(d \mid x=1)} \cdot \tau_{0} \\
& +\frac{\mathrm{P}(x=1) \cdot \mathrm{V}(d \mid x=1)}{\mathrm{P}(x=0) \cdot \mathrm{V}(d \mid x=0)+\mathrm{P}(x=1) \cdot \mathrm{V}(d \mid x=1)} \cdot \tau_{1},
\end{aligned}
$$

where $\tau_{1}$ and $\tau_{0}$ denote the stratum-specific effects. Theorem 1 might appear at first sight to be similar to this result. There are, however, at least two major differences between these formulations: first, Theorem 1 conditions on $d$, while Angrist (1998) conditions on $x$, and therefore does not specify his result in terms of group-specific average partial effects; second, Angrist (1998) does not recover a pattern of "weight reversal", whose manifestation is the main result of this paper. In this appendix I show that equation (24), i.e. the result in Angrist (1998), can be derived from a special case of Lemma 1 (and Theorem 1).

If we apply Lemma 1 to $\tau_{n}$ in $\mathrm{L}(y \mid 1, d, x)=\alpha_{n}+\tau_{n} d+\beta_{n} x$, i.e. to the model in Angrist (1998), we get

$$
\begin{aligned}
\tau_{n} & =\frac{\rho \cdot \mathrm{V}(x \mid d=1) \cdot\left[\mathrm{P}(x=0 \mid d=0) \cdot \tau_{0}+\mathrm{P}(x=1 \mid d=0) \cdot \tau_{1}\right]}{\rho \cdot \mathrm{V}(x \mid d=1)+(1-\rho) \cdot \mathrm{V}(x \mid d=0)} \\
& +\frac{(1-\rho) \cdot \mathrm{V}(x \mid d=0) \cdot\left[\mathrm{P}(x=0 \mid d=1) \cdot \tau_{0}+\mathrm{P}(x=1 \mid d=1) \cdot \tau_{1}\right]}{\rho \cdot \mathrm{V}(x \mid d=1)+(1-\rho) \cdot \mathrm{V}(x \mid d=0)} \\
& =\frac{\rho \cdot \mathrm{V}(x \mid d=1) \cdot \mathrm{P}(x=0 \mid d=0)}{\rho \cdot \mathrm{V}(x \mid d=1)+(1-\rho) \cdot \mathrm{V}(x \mid d=0)} \cdot \tau_{0} \\
& +\frac{(1-\rho) \cdot \mathrm{V}(x \mid d=0) \cdot \mathrm{P}(x=0 \mid d=1)}{\rho \cdot \mathrm{V}(x \mid d=1)+(1-\rho) \cdot \mathrm{V}(x \mid d=0)} \cdot \tau_{0} \\
+ & \frac{\rho \cdot \mathrm{V}(x \mid d=1) \cdot \mathrm{P}(x=1 \mid d=0)}{\rho \cdot \mathrm{V}(x \mid d=1)+(1-\rho) \cdot \mathrm{V}(x \mid d=0)} \cdot \tau_{1} \\
+ & \frac{(1-\rho) \cdot \mathrm{V}(x \mid d=0) \cdot \mathrm{P}(x=1 \mid d=1)}{\rho \cdot \mathrm{V}(x \mid d=1)+(1-\rho) \cdot \mathrm{V}(x \mid d=0)} \cdot \tau_{1},
\end{aligned}
$$

which can be further rearranged using Bayes' theorem. Indeed,

$$
\tau_{n}=\frac{\mathrm{P}(x=0) \cdot \mathrm{V}(d \mid x=0) \cdot \mathrm{P}(d=1 \mid x=1)}{\rho \cdot \mathrm{V}(x \mid d=1)+(1-\rho) \cdot \mathrm{V}(x \mid d=0)} \cdot \frac{\mathrm{P}(x=0) \cdot \mathrm{P}(x=1)}{\rho \cdot(1-\rho)} \cdot \tau_{0}
$$




$$
\begin{aligned}
& +\frac{\mathrm{P}(x=0) \cdot \mathrm{V}(d \mid x=0) \cdot \mathrm{P}(d=0 \mid x=1)}{\rho \cdot \mathrm{V}(x \mid d=1)+(1-\rho) \cdot \mathrm{V}(x \mid d=0)} \cdot \frac{\mathrm{P}(x=0) \cdot \mathrm{P}(x=1)}{\rho \cdot(1-\rho)} \cdot \tau_{0} \\
& +\frac{\mathrm{P}(x=1) \cdot \mathrm{V}(d \mid x=1) \cdot \mathrm{P}(d=1 \mid x=0)}{\rho \cdot \mathrm{V}(x \mid d=1)+(1-\rho) \cdot \mathrm{V}(x \mid d=0)} \cdot \frac{\mathrm{P}(x=0) \cdot \mathrm{P}(x=1)}{\rho \cdot(1-\rho)} \cdot \tau_{1} \\
& +\frac{\mathrm{P}(x=1) \cdot \mathrm{V}(d \mid x=1) \cdot \mathrm{P}(d=0 \mid x=0)}{\rho \cdot \mathrm{V}(x \mid d=1)+(1-\rho) \cdot \mathrm{V}(x \mid d=0)} \cdot \frac{\mathrm{P}(x=0) \cdot \mathrm{P}(x=1)}{\rho \cdot(1-\rho)} \cdot \tau_{1} \\
& =\frac{\mathrm{P}(x=0) \cdot \mathrm{V}(d \mid x=0)}{\rho \cdot \mathrm{V}(x \mid d=1)+(1-\rho) \cdot \mathrm{V}(x \mid d=0)} \cdot \frac{\mathrm{P}(x=0) \cdot \mathrm{P}(x=1)}{\rho \cdot(1-\rho)} \cdot \tau_{0} \\
& +\frac{\mathrm{P}(x=1) \cdot \mathrm{V}(d \mid x=1)}{\rho \cdot \mathrm{V}(x \mid d=1)+(1-\rho) \cdot \mathrm{V}(x \mid d=0)} \cdot \frac{\mathrm{P}(x=0) \cdot \mathrm{P}(x=1)}{\rho \cdot(1-\rho)} \cdot \tau_{1} \\
& =\frac{\mathrm{P}(x=0) \cdot \mathrm{V}(d \mid x=0)}{\mathrm{P}(x=0) \cdot \mathrm{V}(d \mid x=0)+\mathrm{P}(x=1) \cdot \mathrm{V}(d \mid x=1)} \cdot \tau_{0} \\
& +\frac{\mathrm{P}(x=1) \cdot \mathrm{V}(d \mid x=1)}{\mathrm{P}(x=0) \cdot \mathrm{V}(d \mid x=0)+\mathrm{P}(x=1) \cdot \mathrm{V}(d \mid x=1)} \cdot \tau_{1}
\end{aligned}
$$

where the last equality, again, follows from Bayes' theorem. More precisely,

$$
\begin{aligned}
\frac{\rho \cdot(1-\rho) \cdot \rho \cdot \mathrm{V}(x \mid d=1)}{\mathrm{P}(x=0) \cdot \mathrm{P}(x=1)} & =(1-\rho) \cdot \mathrm{P}(d=1 \mid x=1) \cdot \mathrm{P}(d=1 \mid x=0) \\
& =\mathrm{P}(x=0) \cdot \mathrm{V}(d \mid x=0) \cdot \mathrm{P}(d=1 \mid x=1) \\
& +\mathrm{P}(x=1) \cdot \mathrm{V}(d \mid x=1) \cdot \mathrm{P}(d=1 \mid x=0) \\
& =\lambda_{1}
\end{aligned}
$$

and also

$$
\begin{aligned}
\frac{\rho \cdot(1-\rho) \cdot(1-\rho) \cdot \mathrm{V}(x \mid d=0)}{\mathrm{P}(x=0) \cdot \mathrm{P}(x=1)} & =\rho \cdot \mathrm{P}(d=0 \mid x=1) \cdot \mathrm{P}(d=0 \mid x=0) \\
& =\mathrm{P}(x=0) \cdot \mathrm{V}(d \mid x=0) \cdot \mathrm{P}(d=0 \mid x=1) \\
& +\mathrm{P}(x=1) \cdot \mathrm{V}(d \mid x=1) \cdot \mathrm{P}(d=0 \mid x=0) \\
& =\lambda_{0},
\end{aligned}
$$

which leads to

$$
\lambda_{0}+\lambda_{1}=\mathrm{P}(x=0) \cdot \mathrm{V}(d \mid x=0)+\mathrm{P}(x=1) \cdot \mathrm{V}(d \mid x=1) .
$$

The equivalence between equations (24) and (26) confirms that the result in Angrist (1998) can be derived from a special case of Lemma 1, in which both $d$ and $x$ are binary. 


\section{Further Monte Carlo Results}

Figure C3: Linear Regression and LPM-Based Estimates of Average Treatment Effects

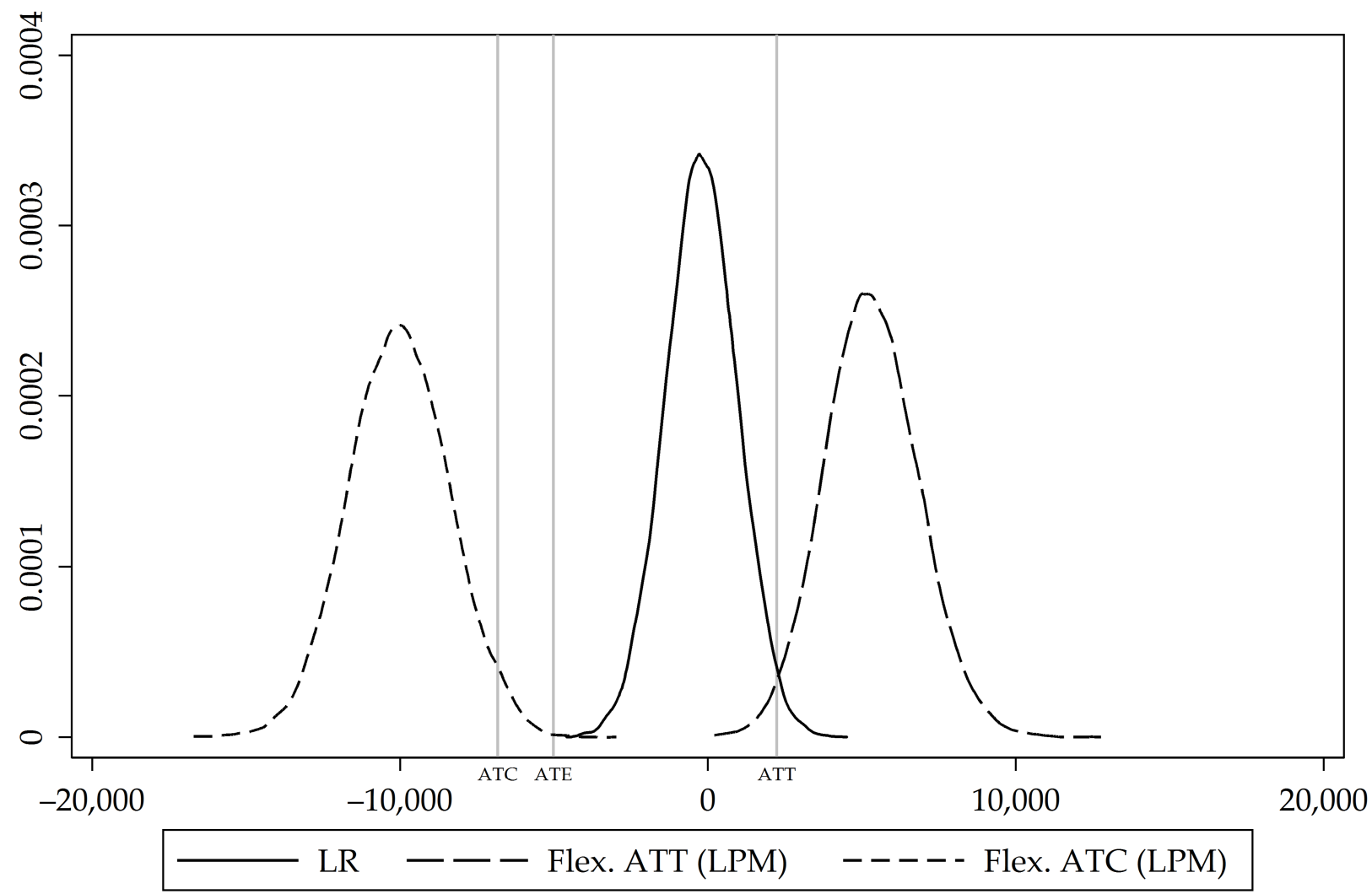

Table C7: Simulation Results of the First MC Study

\begin{tabular}{llccccc}
\hline \hline Method & Parameter & Mean bias & Median bias & RMSE & MAE & SD \\
\hline LR & ATE & 4,812 & 4,810 & 4,952 & 4,810 & 1,170 \\
LR & ATT & $-2,439$ & $-2,441$ & 2,705 & 2,441 & 1,170 \\
LR & ATC & 6,625 & 6,623 & 6,727 & 6,623 & 1,170 \\
Flex. ATE & ATE & 40 & 22 & 2,601 & 1,726 & 2,601 \\
Flex. ATT & ATT & -125 & -133 & 1,368 & 922 & 1,362 \\
Flex. ATC & ATC & 76 & 42 & 3,188 & 2,114 & 3,187 \\
Flex. ATT (LPM) & ATT & 3,093 & 3,047 & 3,454 & 3,047 & 1,537 \\
Flex. ATC (LPM) & ATC & $-3,193$ & $-3,201$ & 3,590 & 3,201 & 1,642 \\
\hline
\end{tabular}

Notes: "Method" refers to the estimation method. "Parameter" refers to the parameter of interest, against which biases are calculated. "LR" denotes linear least squares regression. "Flex. ATE", "Flex. ATT", and "Flex. ATC" denote various versions of the "flexible OLS" estimator. "Flex. ATT (LPM)" and "Flex. ATC (LPM)" denote various versions of the LPM-based "flexible OLS" estimator. See the text for details. 
Table C8: Implicit Weights on $\hat{\tau}_{A T T}$ and $\hat{\tau}_{A T C}$ in the First MC Study

\begin{tabular}{lcccc}
\hline \hline & Mean & SD & Minimum & Maximum \\
\hline $\mathrm{P}(d=1)$ & 0.200 & 0.014 & 0.146 & 0.260 \\
$\mathrm{P}(d=0)$ & 0.800 & 0.014 & 0.740 & 0.854 \\
$w_{A T T}$ & 0.640 & 0.038 & 0.457 & 0.767 \\
$w_{A T C}$ & 0.360 & 0.038 & 0.233 & 0.543 \\
\hline
\end{tabular}

Notes: $\mathrm{P}(d=1)$ denotes the proportion of treated units. $\mathrm{P}(d=0)$ denotes the proportion of control units. The implicit weights on $\hat{\tau}_{A T T}$ and $\hat{\tau}_{A T C}$ are denoted by $w_{A T T}$ and $w_{A T C}$, respectively.

Table C9: Simulation Results of the Second MC Study

\begin{tabular}{cccccc}
\hline \hline $\mathrm{P}(d=1)$ & Mean bias & Median bias & RMSE & MAE & SD \\
\hline & \multicolumn{5}{c}{ Panel A: ATT } \\
0.200 & $-2,304$ & $-2,273$ & 2,398 & 2,273 & 662 \\
0.221 & $-2,485$ & $-2,457$ & 2,577 & 2,457 & 685 \\
0.247 & $-2,638$ & $-2,622$ & 2,735 & 2,622 & 722 \\
0.281 & $-2,881$ & $-2,849$ & 2,985 & 2,849 & 781 \\
0.324 & $-3,100$ & $-3,030$ & 3,225 & 3,030 & 888 \\
0.384 & $-3,399$ & $-3,318$ & 3,535 & 3,318 & 971 \\
0.471 & $-3,761$ & $-3,647$ & 3,926 & 3,647 & 1,128 \\
0.609 & $-4,380$ & $-4,195$ & 4,607 & 4,195 & 1,428 \\
0.862 & $-5,962$ & $-5,647$ & 6,411 & 5,647 & 2,357 \\
& & & & \\
0.200 & & & Panel B: ATC & \\
0.221 & 6,759 & 6,791 & 6,791 & 662 \\
0.247 & 6,579 & 6,606 & 6,614 & 6,791 & 685 \\
0.281 & 6,426 & 6,442 & 6,466 & 6,442 & 722 \\
0.324 & 6,182 & 6,214 & 6,232 & 6,214 & 881 \\
0.384 & 5,963 & 6,034 & 6,029 & 6,034 & 971 \\
0.471 & 5,665 & 5,745 & 5,747 & 5,745 & 1,128 \\
0.609 & 5,303 & 5,416 & 5,421 & 5,416 & 2,428 \\
0.862 & 4,683 & 4,869 & 4,896 & 4,869 & 2,357 \\
\hline
\end{tabular}

Notes: $\mathrm{P}(d=1)$ denotes the proportion of treated units. Simulation results are reported for linear least squares regression. Biases are calculated against either the average treatment effect on the treated (Panel A) or the average treatment effect on the controls (Panel B). 
Table C10: Implicit Weights on $\hat{\tau}_{A T T}$ and $\hat{\tau}_{A T C}$ in the Second MC Study

\begin{tabular}{|c|c|c|c|c|c|c|c|c|}
\hline \multirow[b]{2}{*}{$\mathbf{P}(d=1)$} & \multicolumn{4}{|c|}{$w_{A T T}$} & \multicolumn{4}{|c|}{$w_{A T C}$} \\
\hline & Mean & SD & Minimum & Maximum & Mean & SD & Minimum & Maximum \\
\hline 0.200 & 0.638 & 0.032 & 0.525 & 0.722 & 0.362 & 0.032 & 0.278 & 0.475 \\
\hline 0.221 & 0.618 & 0.035 & 0.485 & 0.726 & 0.382 & 0.035 & 0.274 & 0.515 \\
\hline 0.247 & 0.598 & 0.036 & 0.456 & 0.705 & 0.402 & 0.036 & 0.295 & 0.544 \\
\hline 0.281 & 0.575 & 0.039 & 0.434 & 0.689 & 0.425 & 0.039 & 0.311 & 0.566 \\
\hline 0.324 & 0.551 & 0.041 & 0.376 & 0.674 & 0.449 & 0.041 & 0.326 & 0.624 \\
\hline 0.384 & 0.523 & 0.042 & 0.364 & 0.636 & 0.477 & 0.042 & 0.364 & 0.636 \\
\hline 0.471 & 0.494 & 0.045 & 0.351 & 0.647 & 0.506 & 0.045 & 0.353 & 0.649 \\
\hline 0.609 & 0.459 & 0.048 & 0.321 & 0.619 & 0.541 & 0.048 & 0.381 & 0.679 \\
\hline 0.862 & 0.368 & 0.072 & 0.128 & 0.593 & 0.632 & 0.072 & 0.407 & 0.872 \\
\hline
\end{tabular}

Notes: $\mathrm{P}(d=1)$ denotes the proportion of treated units. The implicit weights on $\hat{\tau}_{A T T}$ and $\hat{\tau}_{A T C}$ are denoted by $w_{A T T}$ and $w_{A T C}$, respectively. 


\section{Further Results on the Effects of Local Officials}

Table D11: A Replication of Martinez-Bravo (2014)—The Effects on Golkar Victory

\begin{tabular}{lcccccc}
\hline \hline & $\begin{array}{c}\text { Whole } \\
\text { sample }\end{array}$ & $\begin{array}{c}\text { PDI-P won } \\
\text { large 1999 }\end{array}$ & $\begin{array}{c}\text { PDI-P just } \\
\text { won 1999 }\end{array}$ & $\begin{array}{c}\text { Golkar just } \\
\text { won 1999 }\end{array}$ & $\begin{array}{c}\text { Golkar won } \\
\text { large 1999 }\end{array}$ & $\begin{array}{c}\text { Neither } \\
\text { won }\end{array}$ \\
\cline { 2 - 7 } Kelurahan indicator & $0.055^{* * *}$ & 0.002 & $0.076^{* *}$ & $0.128^{* * *}$ & $0.044^{* *}$ & $0.068^{*}$ \\
& $(0.012)$ & $(0.016)$ & $(0.029)$ & $(0.037)$ & $(0.018)$ & $(0.038)$ \\
Observations & 43,394 & 15,430 & 9,114 & 5,946 & 7,378 & 5,526 \\
& & \multicolumn{7}{c}{ Linear probability model } \\
Kelurahan indicator & $0.033^{* * *}$ & 0.001 & $0.034^{* * *}$ & $0.136^{* * *}$ & $0.047^{* * *}$ & 0.028 \\
Observations & $(0.009)$ & $(0.006)$ & $(0.010)$ & $(0.050)$ & $(0.016)$ & $(0.025)$ \\
\hline
\end{tabular}

Notes: See also Martinez-Bravo (2014) for more details on these data. The unit of observation is a village. The dependent variable equals one if Golkar was the most voted party in the village in the 1999 parliamentary election and zero otherwise. All regressions include geographic controls, religious controls, facilities controls, and district fixed effects. Estimation is based on linear least squares regression, with controls for either the variables listed in the table ("Linear probability model") or the propensity-score strata, province fixed effects, and the full set of interactions between the strata and the fixed effects ("Propensity score model"). In the latter case, the variables listed in the table correspond to the propensity score specifications. Cluster-robust standard errors ("Linear probability model") and bootstrap standard errors ("Propensity score model") are in parentheses.

*Statistically significant at the $10 \%$ level; **at the $5 \%$ level; ***at the $1 \%$ level.

Table D12: A Replication of Martinez-Bravo (2014)—The Effects on PDI-P Victory

\begin{tabular}{lcccccc}
\hline \hline & $\begin{array}{c}\text { Whole } \\
\text { sample }\end{array}$ & $\begin{array}{c}\text { PDI-P won } \\
\text { large 1999 }\end{array}$ & $\begin{array}{c}\text { PDI-P just } \\
\text { won 1999 }\end{array}$ & $\begin{array}{c}\text { Golkar just } \\
\text { won 1999 }\end{array}$ & $\begin{array}{c}\text { Golkar won } \\
\text { large 1999 }\end{array}$ & $\begin{array}{c}\text { Neither } \\
\text { won }\end{array}$ \\
\hline \multirow{3}{*}{ Kelurahan indicator } & \multicolumn{7}{c}{ Linear probability model } \\
\cline { 2 - 7 } Observations & -0.021 & $0.037^{*}$ & -0.037 & $-0.087^{*}$ & -0.024 & -0.004 \\
& $(0.014)$ & $(0.021)$ & $(0.045)$ & $(0.043)$ & $(0.015)$ & $(0.045)$ \\
Kelurahan indicator & 43,394 & 15,430 & 9,114 & 5,946 & 7,378 & 5,526 \\
\cline { 2 - 7 } & -0.003 & $0.033^{* * *}$ & -0.008 & $-0.099^{* * *}$ & $-0.021^{*}$ & -0.023 \\
Observations & $(0.010)$ & $(0.009)$ & $(0.039)$ & $(0.036)$ & $(0.011)$ & $(0.045)$ \\
\hline
\end{tabular}

Notes: See also Martinez-Bravo (2014) for more details on these data. The unit of observation is a village. The dependent variable equals one if PDI-P was the most voted party in the village in the 1999 parliamentary election and zero otherwise. All regressions include geographic controls, religious controls, facilities controls, and district fixed effects. Estimation is based on linear least squares regression, with controls for either the variables listed in the table ("Linear probability model") or the propensity-score strata, province fixed effects, and the full set of interactions between the strata and the fixed effects ("Propensity score model"). In the latter case, the variables listed in the table correspond to the propensity score specifications. Cluster-robust standard errors ("Linear probability model") and bootstrap standard errors ("Propensity score model") are in parentheses.

*Statistically significant at the $10 \%$ level; **at the $5 \%$ level; *** at the $1 \%$ level. 
Table D13: Martinez-Bravo (2014) and Treatment Effect Heterogeneity—The Effects on Golkar Victory

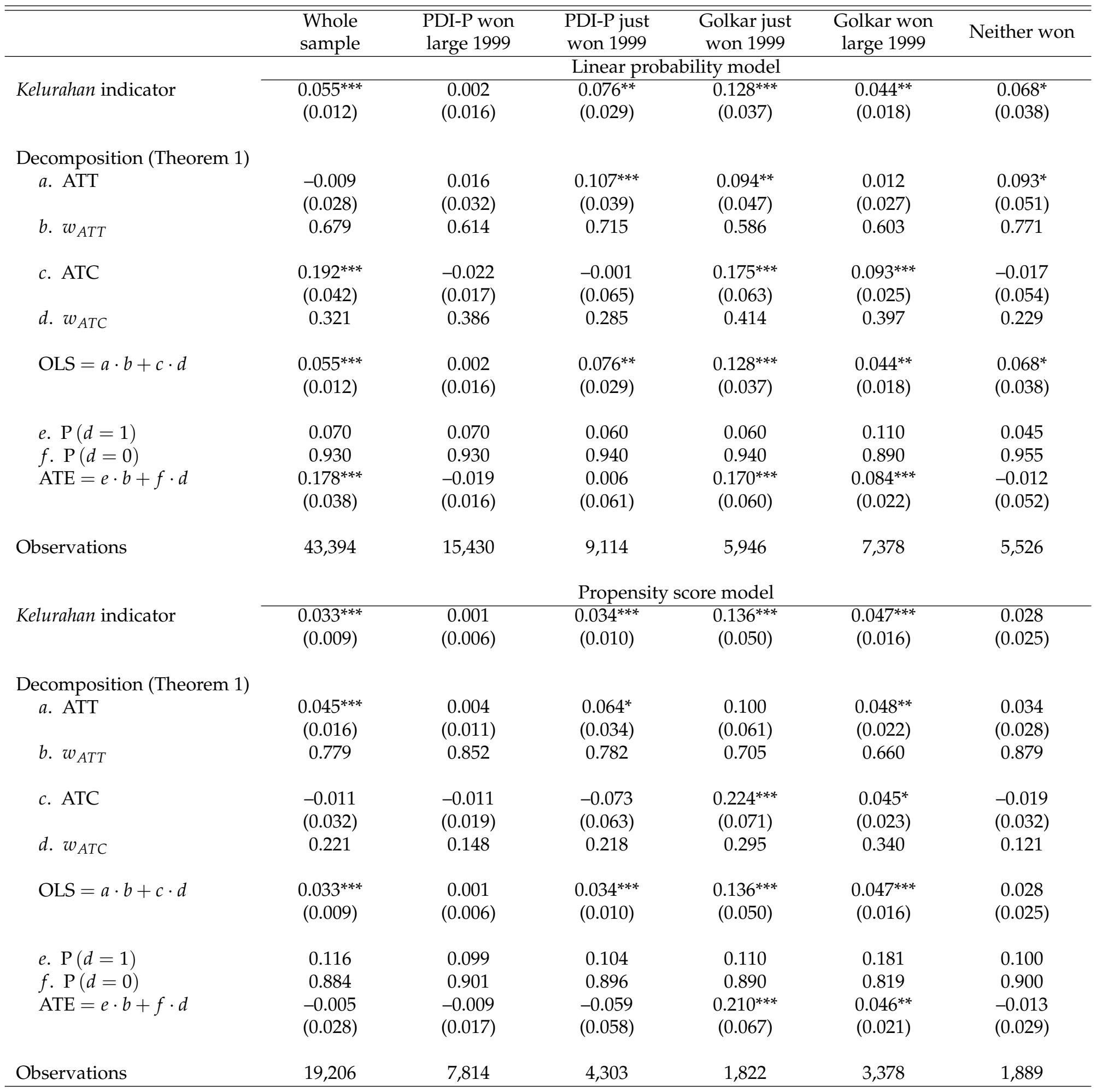

Notes: See also Martinez-Bravo (2014) for more details on these data. The unit of observation is a village. The dependent variable equals one if Golkar was the most voted party in the village in the 1999 parliamentary election and zero otherwise. All regressions and propensity score specifications include geographic controls, religious controls, facilities controls, and district fixed effects. Estimation of "Kelurahan indicator" (=OLS) is based on linear least squares regression, with controls for either the variables listed in the table ("Linear probability model") or the propensity-score strata, province fixed effects, and the full set of interactions between the strata and the fixed effects ("Propensity score model"). In the latter case, the variables listed in the table correspond to the propensity score specifications. Estimation of ATT and ATC is described in Section 2 (in particular, see Theorem 1). Cluster-robust standard errors ("Linear probability model", OLS), bootstrap standard errors ("Propensity score model", OLS), and Huber-White standard errors (ATT, ATC, and ATE) are in parentheses. Huber-White standard errors ignore that the propensity score is estimated. *Statistically significant at the $10 \%$ level; **at the $5 \%$ level; ***at the $1 \%$ level. 
Table D14: Martinez-Bravo (2014) and Treatment Effect Heterogeneity-The Effects on PDI-P Victory

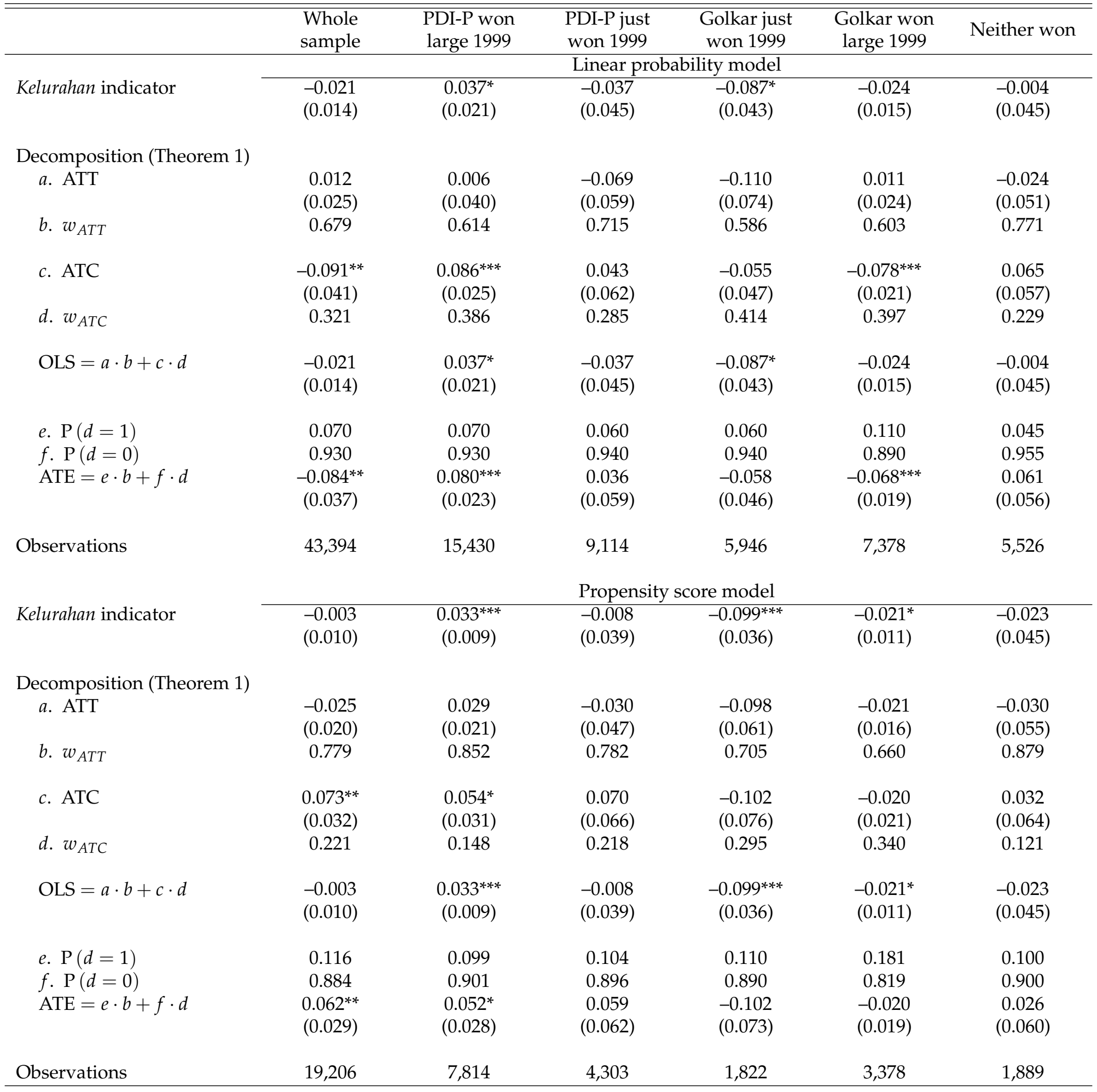

Notes: See also Martinez-Bravo (2014) for more details on these data. The unit of observation is a village. The dependent variable equals one if PDI-P was the most voted party in the village in the 1999 parliamentary election and zero otherwise. All regressions and propensity score specifications include geographic controls, religious controls, facilities controls, and district fixed effects. Estimation of "Kelurahan indicator" (=OLS) is based on linear least squares regression, with controls for either the variables listed in the table ("Linear probability model") or the propensity-score strata, province fixed effects, and the full set of interactions between the strata and the fixed effects ("Propensity score model"). In the latter case, the variables listed in the table correspond to the propensity score specifications. Estimation of ATT and ATC is described in Section 2 (in particular, see Theorem 1). Cluster-robust standard errors ("Linear probability model", OLS), bootstrap standard errors ("Propensity score model", OLS), and Huber-White standard errors (ATT, ATC, and ATE) are in parentheses. Huber-White standard errors ignore that the propensity score is estimated. *Statistically significant at the $10 \%$ level; **at the $5 \%$ level; ***at the $1 \%$ level. 
Table D15: Further Estimates of the Effects of Local Officials on Golkar Victory (Overlap Sample)

\begin{tabular}{|c|c|c|c|c|c|c|}
\hline & $\begin{array}{l}\text { Whole } \\
\text { sample }\end{array}$ & $\begin{array}{l}\text { PDI-P won } \\
\text { large } 1999\end{array}$ & $\begin{array}{l}\text { PDI-P just } \\
\text { won } 1999\end{array}$ & $\begin{array}{c}\text { Golkar just } \\
\text { won } 1999\end{array}$ & $\begin{array}{c}\text { Golkar won } \\
\text { large } 1999\end{array}$ & Neither won \\
\hline OLS-LPM & $\begin{array}{c}0.035^{* * *} \\
(0.011)\end{array}$ & $\begin{array}{l}-0.001 \\
(0.014)\end{array}$ & $\begin{array}{l}0.050^{*} \\
(0.028)\end{array}$ & $\begin{array}{c}0.106^{* * *} \\
(0.038)\end{array}$ & $\begin{array}{l}0.045^{* *} \\
(0.018)\end{array}$ & $\begin{array}{c}0.032 \\
(0.029)\end{array}$ \\
\hline ATT-LPM & $\begin{array}{l}0.036^{*} \\
(0.020)\end{array}$ & $\begin{array}{c}-0.044^{* *} \\
(0.022)\end{array}$ & $\begin{array}{l}0.067^{* *} \\
(0.034)\end{array}$ & $\begin{array}{c}0.070 \\
(0.069)\end{array}$ & $\begin{array}{c}0.069^{* * *} \\
(0.026)\end{array}$ & $\begin{array}{l}-0.016 \\
(0.049)\end{array}$ \\
\hline ATE-LPM & $\begin{array}{c}0.097^{* * * *} \\
(0.033)\end{array}$ & $\begin{array}{l}-0.005 \\
(0.032)\end{array}$ & $\begin{array}{c}0.004 \\
(0.073)\end{array}$ & $\begin{array}{c}0.078 \\
(0.109)\end{array}$ & $\begin{array}{c}0.079^{* * *} \\
(0.029)\end{array}$ & $\begin{array}{l}0.164^{*} \\
(0.094)\end{array}$ \\
\hline OLS-probit & $\begin{array}{c}0.033^{* * *} \\
(0.009)\end{array}$ & $\begin{array}{c}0.001 \\
(0.006)\end{array}$ & $\begin{array}{c}0.034^{* * *} \\
(0.010)\end{array}$ & $\begin{array}{c}0.136^{* * *} \\
(0.050)\end{array}$ & $\begin{array}{c}0.047^{* * *} \\
(0.016)\end{array}$ & $\begin{array}{c}0.028 \\
(0.025)\end{array}$ \\
\hline ATT-probit & $\begin{array}{l}0.031^{*} \\
(0.016)\end{array}$ & $\begin{array}{l}-0.006 \\
(0.022)\end{array}$ & $\begin{array}{c}0.000 \\
(0.042)\end{array}$ & $\begin{array}{c}0.104 \\
(0.081)\end{array}$ & $\begin{array}{l}0.044^{*} \\
(0.026)\end{array}$ & $\begin{array}{c}0.016 \\
(0.049)\end{array}$ \\
\hline ATE-probit & $\begin{array}{l}-0.001 \\
(0.031)\end{array}$ & $\begin{array}{l}-0.008 \\
(0.044)\end{array}$ & $\begin{array}{c}0.037 \\
(0.076)\end{array}$ & $\begin{array}{c}0.131 \\
(0.142)\end{array}$ & $\begin{array}{l}0.070^{* * *} \\
(0.032)\end{array}$ & $\begin{array}{l}-0.037 \\
(0.069)\end{array}$ \\
\hline Observations & 19,206 & 7,814 & 4,303 & 1,822 & 3,378 & 1,889 \\
\hline
\end{tabular}

Notes: See also Martinez-Bravo (2014) for more details on these data. The unit of observation is a village. The dependent variable equals one if Golkar was the most voted party in the village in the 1999 parliamentary election and zero otherwise. All regressions and propensity score specifications include geographic controls, religious controls, facilities controls, and district fixed effects. For "OLS-LPM" and "OLS-probit", estimation is based on linear least squares regression, with controls for either the variables listed above ("OLS-LPM") or the propensity-score strata, province fixed effects, and the full set of interactions between the strata and the fixed effects ("OLS-probit"). In the latter case, the variables listed above correspond to the propensity score specifications. For "ATT-LPM", "ATE-LPM", "ATT-probit", and "ATE-probit", estimation is based on nearest-neighbor matching on the estimated propensity score (with a single match). For "ATT-probit" and "ATE-probit", exact matching on province fixed effects is also required. The propensity score is estimated using a linear probability model ("ATT-LPM" and "ATE-LPM") or an algorithm based on a probit model ("ATT-probit" and "ATE-probit"). A description of this algorithm is given in Martinez-Bravo (2014). Cluster-robust standard errors ("OLS-LPM"), bootstrap standard errors ("OLS-probit"), and Abadie-Imbens standard errors ("ATT-LPM", "ATE-LPM", "ATT-probit", and "ATE-probit") are in parentheses. Abadie-Imbens standard errors ignore that the propensity score is estimated.

*Statistically significant at the $10 \%$ level; **at the $5 \%$ level; ${ }^{* * *}$ at the $1 \%$ level. 
Table D16: Further Estimates of the Effects of Local Officials on PDI-P Victory (Overlap Sample)

\begin{tabular}{|c|c|c|c|c|c|c|}
\hline & $\begin{array}{l}\text { Whole } \\
\text { sample }\end{array}$ & $\begin{array}{l}\text { PDI-P won } \\
\text { large } 1999\end{array}$ & $\begin{array}{l}\text { PDI-P just } \\
\text { won } 1999\end{array}$ & $\begin{array}{c}\text { Golkar just } \\
\text { won } 1999\end{array}$ & $\begin{array}{c}\text { Golkar won } \\
\text { large } 1999\end{array}$ & Neither won \\
\hline OLS-LPM & $\begin{array}{l}-0.008 \\
(0.014)\end{array}$ & $\begin{array}{c}0.029 \\
(0.019)\end{array}$ & $\begin{array}{l}-0.007 \\
(0.043)\end{array}$ & $\begin{array}{l}-0.081 \\
(0.049)\end{array}$ & $\begin{array}{l}-0.015 \\
(0.016)\end{array}$ & $\begin{array}{l}-0.050 \\
(0.053)\end{array}$ \\
\hline ATT-LPM & $\begin{array}{c}0.008 \\
(0.021)\end{array}$ & $\begin{array}{c}0.081^{* * *} \\
(0.028)\end{array}$ & $\begin{array}{l}-0.045 \\
(0.044)\end{array}$ & $\begin{array}{c}0.010 \\
(0.061)\end{array}$ & $\begin{array}{l}-0.033 \\
(0.020)\end{array}$ & $\begin{array}{c}0.016 \\
(0.082)\end{array}$ \\
\hline ATE-LPM & $\begin{array}{l}-0.040 \\
(0.035)\end{array}$ & $\begin{array}{c}0.010 \\
(0.043)\end{array}$ & $\begin{array}{c}0.101 \\
(0.094)\end{array}$ & $\begin{array}{c}-0.161^{*} \\
(0.088)\end{array}$ & $\begin{array}{l}-0.035 \\
(0.023)\end{array}$ & $\begin{array}{l}-0.097 \\
(0.099)\end{array}$ \\
\hline OLS-probit & $\begin{array}{l}-0.003 \\
(0.010)\end{array}$ & $\begin{array}{c}0.033^{* * *} \\
(0.009)\end{array}$ & $\begin{array}{l}-0.008 \\
(0.039)\end{array}$ & $\begin{array}{c}-0.099 * * * \\
(0.036)\end{array}$ & $\begin{array}{c}-0.021^{*} \\
(0.011)\end{array}$ & $\begin{array}{l}-0.023 \\
(0.045)\end{array}$ \\
\hline ATT-probit & $\begin{array}{l}-0.008 \\
(0.020)\end{array}$ & $\begin{array}{c}0.043 \\
(0.030)\end{array}$ & $\begin{array}{l}-0.034 \\
(0.053)\end{array}$ & $\begin{array}{l}-0.055 \\
(0.078)\end{array}$ & $\begin{array}{l}-0.015 \\
(0.020)\end{array}$ & $\begin{array}{l}-0.037 \\
(0.092)\end{array}$ \\
\hline ATE-probit & $\begin{array}{c}0.014 \\
(0.041)\end{array}$ & $\begin{array}{c}0.037 \\
(0.058)\end{array}$ & $\begin{array}{c}0.122 \\
(0.099)\end{array}$ & $\begin{array}{l}-0.087 \\
(0.123)\end{array}$ & $\begin{array}{l}-0.033 \\
(0.026)\end{array}$ & $\begin{array}{l}-0.107 \\
(0.122)\end{array}$ \\
\hline Observations & 19,206 & 7,814 & 4,303 & 1,822 & 3,378 & 1,889 \\
\hline
\end{tabular}

Notes: See also Martinez-Bravo (2014) for more details on these data. The unit of observation is a village. The dependent variable equals one if PDI-P was the most voted party in the village in the 1999 parliamentary election and zero otherwise. All regressions and propensity score specifications include geographic controls, religious controls, facilities controls, and district fixed effects. For "OLS-LPM" and "OLS-probit", estimation is based on linear least squares regression, with controls for either the variables listed above ("OLS-LPM") or the propensity-score strata, province fixed effects, and the full set of interactions between the strata and the fixed effects ("OLS-probit"). In the latter case, the variables listed above correspond to the propensity score specifications. For "ATT-LPM", "ATE-LPM", "ATT-probit", and "ATE-probit", estimation is based on nearest-neighbor matching on the estimated propensity score (with a single match). For "ATT-probit" and "ATE-probit", exact matching on province fixed effects is also required. The propensity score is estimated using a linear probability model ("ATT-LPM" and "ATE-LPM") or an algorithm based on a probit model ("ATT-probit" and "ATE-probit"). A description of this algorithm is given in Martinez-Bravo (2014). Cluster-robust standard errors ("OLS-LPM"), bootstrap standard errors ("OLS-probit"), and Abadie-Imbens standard errors ("ATT-LPM", "ATE-LPM", "ATT-probit", and "ATE-probit") are in parentheses. Abadie-Imbens standard errors ignore that the propensity score is estimated.

*Statistically significant at the $10 \%$ level; **at the $5 \%$ level; ***at the $1 \%$ level. 


\section{References}

Alesina, A., Giuliano, P. \& NunN, N. (2013). On the origins of gender roles: Women and the plough. Quarterly Journal of Economics 128, 469-530.

Almond, D., Chay, K. Y. \& Lee, D. S. (2005). The costs of low birth weight. Quarterly Journal of Economics 120, 1031-1083.

ANGRIST, J. D. (1998). Estimating the labor market impact of voluntary military service using Social Security data on military applicants. Econometrica 66, 249-288.

Angrist, J. D., GRAdDY, K. \& IMBENS, G. W. (2000). The interpretation of instrumental variables estimators in simultaneous equations models with an application to the demand for fish. Review of Economic Studies 67, 499-527.

ANGRist, J. D. \& KRUEger, A. B. (1999). Empirical strategies in labor economics. In: Handbook of Labor Economics (ASHENFELTER, O. \& CARD, D., eds.), vol. 3A. NorthHolland.

AngRist, J. D. \& PISCHKe, J.-S. (2009). Mostly Harmless Econometrics: An Empiricist's Companion. Princeton University Press.

ARONOW, P. M. \& SAMII, C. (2015). Does regression produce representative estimates of causal effects? American Journal of Political Science (forthcoming).

Berger, D., Easterly, W., NunN, N. \& Satyanath, S. (2013). Commercial imperialism? Political influence and trade during the Cold War. American Economic Review 103, 863-896.

Bitler, M. P., Gelbach, J. B. \& Hoynes, H. W. (2006). What mean impacts miss: Distributional effects of welfare reform experiments. American Economic Review 96, 9881012.

Bitler, M. P., Gelbach, J. B. \& Hoynes, H. W. (2008). Distributional impacts of the Self-Sufficiency Project. Journal of Public Economics 92, 748-765.

Black, D. A., Smith, J. A., Berger, M. C. \& Noel, B. J. (2003). Is the threat of reemployment services more effective than the services themselves? Evidence from random assignment in the UI system. American Economic Review 93, 1313-1327.

BLINDER, A. S. (1973). Wage discrimination: Reduced form and structural estimates. Journal of Human Resources 8, 436-455. 
BOND, T. N. \& LANG, K. (2013). The evolution of the black-white test score gap in grades K-3: The fragility of results. Review of Economics and Statistics 95, 1468-1479.

Busso, M., DiNARDO, J. \& MCCRARY, J. (2014). New evidence on the finite sample properties of propensity score reweighting and matching estimators. Review of Economics and Statistics 96, 885-897.

Chernozhukov, V., Fernández-Val, I., Hahn, J. \& Newey, W. (2013). Average and quantile effects in nonseparable panel models. Econometrica 81, 535-580.

Crump, R. K., Hotz, V. J., Imbens, G. W. \& Mitnik, O. A. (2008). Nonparametric tests for treatment effect heterogeneity. Review of Economics and Statistics 90, 389-405.

Deaton, A. (1997). The Analysis of Household Surveys: A Microeconometric Approach to Development Policy. Johns Hopkins University Press.

DEATON, A. (2010). Instruments, randomization, and learning about development. Journal of Economic Literature 48, 424-455.

Dieterle, S. \& SNell, A. (2014). Exploiting nonlinearities in the first stage regressions of IV procedures. Unpublished.

Elder, T. E., GODDEERIS, J. H. \& HAIDER, S. J. (2010). Unexplained gaps and OaxacaBlinder decompositions. Labour Economics 17, 284-290.

Fortin, N., Lemieux, T. \& Firpo, S. (2011). Decomposition methods in economics. In: Handbook of Labor Economics (AsHENFELTER, O. \& CARD, D., eds.), vol. 4A. NorthHolland.

FREEDMAN, D. A. (2008a). On regression adjustments in experiments with several treatments. Annals of Applied Statistics 2, 176-196.

FREEDMAN, D. A. (2008b). On regression adjustments to experimental data. Advances in Applied Mathematics 40, 180-193.

FRISCH, R. \& WAUGH, F. V. (1933). Partial time regressions as compared with individual trends. Econometrica 1, 387-401.

Fryer, R. G. \& GreEnStOnE, M. (2010). The changing consequences of attending historically black colleges and universities. American Economic Journal: Applied Economics $2,116-148$. 
FRYER, R. G. \& LEVITT, S. D. (2004). Understanding the black-white test score gap in the first two years of school. Review of Economics and Statistics 86, 447-464.

FrYeR, R. G. \& LEVITT, S. D. (2010). An empirical analysis of the gender gap in mathematics. American Economic Journal: Applied Economics 2, 210-240.

Gibbons, C. E., SuÁrez Serrato, J. C. \& Urbancic, M. B. (2014). Broken or fixed effects? NBER Working Paper no. 20342.

GitTleman, M. \& WOLFF, E. N. (2004). Racial differences in patterns of wealth accumulation. Journal of Human Resources 39, 193-227.

HeCKMAN, J. J. (2001). Micro data, heterogeneity, and the evaluation of public policy: Nobel Lecture. Journal of Political Economy 109, 673-748.

HeCKMAN, J. J., URZUA, S. \& VYTLACIL, E. (2006). Understanding instrumental variables in models with essential heterogeneity. Review of Economics and Statistics 88, 389432.

Heckman, J. J. \& Vytlacil, E. (2005). Structural equations, treatment effects, and econometric policy evaluation. Econometrica 73, 669-738.

HeCKMAN, J. J. \& VYTLACIL, E. J. (2007). Econometric evaluation of social programs, part II: Using the marginal treatment effect to organize alternative econometric estimators to evaluate social programs, and to forecast their effects in new environments. In: Handbook of Econometrics (HeCKMAN, J. J. \& LEAMER, E. E., eds.), vol. 6B. NorthHolland.

Holland, P. W. (1986). Statistics and causal inference. Journal of the American Statistical Association 81, 945-960.

Humphreys, M. (2009). Bounds on least squares estimates of causal effects in the presence of heterogeneous assignment probabilities. Unpublished.

IMAI, K. \& KIM, I. S. (2013). On the use of linear fixed effects regression estimators for causal inference. Unpublished.

IMBENS, G. W. (2015). Matching methods in practice: Three examples. Journal of Human Resources 50, 373-419.

IMBENS, G. W. \& ANGRIST, J. D. (1994). Identification and estimation of local average treatment effects. Econometrica 62, 467-475. 
Imbens, G. W. \& WoOldRIDGE, J. M. (2009). Recent developments in the econometrics of program evaluation. Journal of Economic Literature 47, 5-86.

Khwaja, A., Picone, G., Salm, M. \& Trogdon, J. G. (2011). A comparison of treatment effects estimators using a structural model of AMI treatment choices and severity of illness information from hospital charts. Journal of Applied Econometrics 26, 825-853.

KLINE, P. (2011). Oaxaca-Blinder as a reweighting estimator. American Economic Review: Papers \& Proceedings 101, 532-537.

KLINE, P. (2014). A note on variance estimation for the Oaxaca estimator of average treatment effects. Economics Letters 122, 428-431.

KOLESÁR, M. (2013). Estimation in an instrumental variables model with treatment effect heterogeneity. Unpublished.

LALONDE, R. J. (1986). Evaluating the econometric evaluations of training programs with experimental data. American Economic Review 76, 604-620.

LANG, K. \& MAnOve, M. (2011). Education and labor market discrimination. American Economic Review 101, 1467-1496.

LiN, W. (2013). Agnostic notes on regression adjustments to experimental data: Reexamining Freedman's critique. Annals of Applied Statistics 7, 295-318.

LøKen, K. V., Mogstad, M. \& Wiswall, M. (2012). What linear estimators miss: The effects of family income on child outcomes. American Economic Journal: Applied Economics 4, 1-35.

MARTINEZ-Bravo, M. (2014). The role of local officials in new democracies: Evidence from Indonesia. American Economic Review 104, 1244-1287.

OAXACA, R. (1973). Male-female wage differentials in urban labor markets. International Economic Review 14, 693-709.

RHODES, W. (2010). Heterogeneous treatment effects: What does a regression estimate? Evaluation Review 34, 334-361.

Rosenbaum, P. R. \& Rubin, D. B. (1983). The central role of the propensity score in observational studies for causal effects. Biometrika 70, 41-55.

Rothstein, J. \& Wozny, N. (2013). Permanent income and the black-white test score gap. Journal of Human Resources 48, 509-544. 
SCHOCHET, P. Z. (2010). Is regression adjustment supported by the Neyman model for causal inference? Journal of Statistical Planning and Inference 140, 246-259.

SOlON, G., HAider, S. J. \& WOOldRidGe, J. M. (2015). What are we weighting for? Journal of Human Resources 50, 301-316.

WoOlDRIDGE, J. M. (2005). Fixed-effects and related estimators for correlated randomcoefficient and treatment-effect panel data models. Review of Economics and Statistics 87, 385-390.

Wooldridge, J. M. (2010). Econometric Analysis of Cross Section and Panel Data. MIT Press, 2nd ed.

YITZHAKI, S. (1996). On using linear regressions in welfare economics. Journal of Business $\mathcal{E}$ Economic Statistics 14, 478-486. 